Construction \& Building Materials

Elsevier Editorial System(tm) for

Manuscript Draft

Manuscript Number: CONBUILDMAT-D-15-03994R1

Title: Early Age Performance and Mechanical Characteristics of Recycled PET Fibre Reinforced Concrete

Article Type: Research Paper

Keywords: Fibre reinforced concrete; polyethylene terephthalate (PET); waste recycling; mechanical characteristics; plastic shrinkage; restrained shrinkage

Corresponding Author: Dr. Ruben Paul Borg, PhD, Spec.Struct.Eng, $\mathrm{BE} \& \mathrm{~A}$ (Hons)

Corresponding Author's Institution: University of Malta

First Author: Ruben Paul Borg, PhD, Spec.Struct.Eng, BE\&A(Hons)

Order of Authors: Ruben Paul Borg, PhD, Spec.Struct.Eng, BE\&A(Hons); Owen Baldacchino; Liberato Ferrara, PhD

Abstract: In this study the performance of concrete reinforced with fibres produced from waste non-biodegradable plastic, polyethylene terephthalate (PET), has been thoroughly investigated. The novelty of the study, to the authors' knowledge, consists in the fact that fibres have been employed as directly shredded from collected waste plastic bottles, with no processing through, e.g., plastic melting and fibre spinning. Moreover, a comprehensive investigation has been herein undertaken, which ranges from the identification of the mechanical behavior of the fibres to the assessment of their bond with the matrix and of the early age and hardened state properties of the Recycled PET Fibre Reinforced Concrete. Different types of shredded Recycled PET fibres, straight and deformed, together with different fibre lengths, $30 \mathrm{~mm}$ and $50 \mathrm{~mm}$, have been assessed, for varying percentage addition in concrete. The tensile properties and pull out characteristics of the fibres have been determined. The effects of fibres in mitigating plastic and restrained drying shrinkage cracking were then assessed and, finally, the compressive strength and the flexural performance of the fibre concrete were determined. The cracking potential of fibre-reinforced mortar thin slabs was also assessed. A slight reduction in compressive strength was reported while in the flexural performance assessment, the higher fibre volumes and the deformed fibres provided better residual strengths. In the assessment of plastic shrinkage, the R-PET fibres managed to restrain crack development even at low fibre volume fractions. The longer fibres were found to be more effective, with the deformed fibres performing slightly better than their straight counterparts in restraining crack development. In the case of restrained shrinkage cracking, 1\% of $50 \mathrm{~mm}$ long deformed PET fibres exhibited the best performance, with no cracks observed after 28 days. In the mortar slabs, a reduction in the total crack area was observed in both fibre types with an increase in fibre volume fractions. The use of Shredded Recycled PET fibres in concrete has been shown to lead to significant improvements in performance for various fibre concrete characteristics and offers a potential alternative for this material. 

Covering Letter

Early age performance and mechanical characteristics of recycled PET Fibre Reinforced Concrete by Ruben P. Borg, O. Baldacchino and L. Ferrara

submitted for publication to Construction and Building Materials

The authors would like to thank the reviewers for their careful reading of the manusript and for their insightful comments which are greatly appreciated. The recommendations of the reviewers have all been taken into due consideration in order to improve the quality of the manuscript as required.

Thank you

Ruben Paul Borg

(on behalf of the Authors) 


\section{Response to the reviewers of the manuscript}

\section{Early age performance and mechanical characteristics of recycled PET Fibre Reinforced Concrete by Ruben P. Borg, O. Baldacchino and L. Ferrara}

submitted for publication to Construction and Building Materials

The authors thank the reviewers for their careful reading of the manusript and for their insightful comments which are greatly appreciated. The recommendations of the reviewers have all been taken into due consideration in order to improve the quality of the manuscript as required.

In detail:

\section{$\underline{\text { Reviewer } 1}$}

1. A pertinent sentence has been added.

2. The number of digits in the tables has been checked and made uniform; please consider that their number may differ because of different precision needs in referring different quantities (e.g. the dosage of a $S P$ in the mix design requires more detail than the dosage of sand).

3. the required action has been undertaken.

4. the quality of figures has been enhanced.

5. A sentence has been added: as a matter of fact these concretes are not suitable for structural application, as per Model Code 2010.

6. This comment seems not persuasive to the authors: with only three tests per each type of mix the calculation of the characteristic value is meaningless; the sentence added with reference to bullet point 5 anyway also addresses this issue.

Moreover, required references have been cited

\section{$\underline{\text { Reviewer } 2}$}

Quaity of figures has been improved.

\section{Reviewer 3}

1. Abstract has been revised and shortened

2. The pertinent paragraph of the introduction has been revised and greatly simplified. 
3. The authors believe that keeping separate Table 1 and Table 4 improves the readbility of the manuscript; in Table 1 the experimental matrix is given with details only on the major variables chosen to build up the experimental programme, which gives the reader the necessary information to grasp the gross content and scope of the work whereas in Table 4 the details of the mix design are given. As already explained in the text, the mix design is a typical one to achieve a $30 \mathrm{~N} / \mathrm{mm} 2$ cube compressive strength with the required slump. An explanatory sentence about the rationale of the mortar mix design has been added in the relevant section of the text.

4. Section and figures have been carefully revised. Anyway, due to the amount of data and the wide experimental test matrix the authors believe that the style and structure they have adopted for section 3 still guarantees readability and accompanies the reader through the main findings of their research. 
Early age performance and mechanical characteristics of recycled PET Fibre Reinforced Concrete

by Ruben P. Borg, O. Baldacchino and L. Ferrara

Highlights:

- fibres obtained by shredding recycled PET bottles have been used as dispersed reinforcement in concrete

- effects of fibres on cracking potential due to plastic and restrained drying shrinkage and on mechanical properties have been investigated

- recycled PET fibres can effectively replace industrial fibres in structures sensitive to shrinkage cracking 


\title{
Early Age Performance and Mechanical Characteristics of Recycled PET Fibre Reinforced Concrete
}

\author{
Ruben Paul Borg ${ }^{1}$, Owen Baldacchino ${ }^{1}$, Liberato Ferrara ${ }^{2}$ \\ ${ }^{1}$ Faculty for the Built Environment, University of Malta, Tal-Qroqq, Msida MSD 2080, Malta, \\ ruben.p.borg@um.edu.mt \\ ${ }^{2}$ Department of Civil and Environmental Engineering, Politecnico di Milano, Piazza Leonardo da Vinci, Milano, \\ Italy, liberato.ferrara@polimi.it
}

\begin{abstract}
In this study the performance of concrete reinforced with fibres produced from waste non-biodegradable plastic, polyethylene terephthalate (PET), has been thoroughly investigated. The novelty of the study, to the authors' knowledge, consists in the fact that fibres have been employed as directly shredded from collected waste plastic bottles, with no processing through, e.g., plastic melting and fibre spinning. Moreover, a comprehensive investigation has been herein undertaken, which ranges from the identification of the mechanical behavior of the fibres to the assessment of their bond with the matrix and of the early age and hardened state properties of the Recycled PET Fibre Reinforced Concrete.

Different types of shredded Recycled PET fibres, straight and deformed, together with different fibre lengths, $30 \mathrm{~mm}$ and $50 \mathrm{~mm}$, have been assessed, for varying percentage addition in concrete. The tensile properties and pull out characteristics of the fibres have been determined. The effects of fibres in mitigating plastic and restrained drying shrinkage cracking were then assessed and, finally, the compressive strength and the flexural performance of the fibre concrete were determined. The cracking potential of fibre-reinforced mortar thin slabs was also assessed.

The use of Shredded Recycled PET fibres in concrete has been shown to lead to interesting improvements in performance for various fibre concrete characteristics and offers a potential alternative for this material.
\end{abstract}

\section{Keywords}

Fibre reinforced concrete; polyethylene terephthalate (PET); waste recycling; mechanical characteristics; plastic shrinkage; restrained shrinkage. 


\section{Introduction}

In the field of concrete construction, the use of fibres has been steadily increasing over the past years in an effort to overcome the inborn tensile strength and toughness limitations of plain concrete. The ability to enhance flexural and tensile performance of the concrete matrix, together with the opportunity for improving its durability, pushed boundaries in developing new materials to be used as fibres. As ma matter of fact the introduction of fibres is also known to lead to a reduction in the shrinkage cracking of the concrete matrix, which affects both the aesthetics and the service life of structures.

Concrete reinforced with polymer and steel fibres (Fibre Reinforced Concrete - FRC) belongs to the socalled composite materials. Compared to plain concrete, FRC is characterized by improved crack control, better fatigue resistance and greater tensile and flexural performance. The level of fibre performance depends strongly on the quality and amount of the employed fibres applied, on their shape and dimensions as well as on their bond to the concrete matrix.

The environmental problems related to the management of numerous different types of waste have led to assess the possibility of their use as constituents in the concrete. Commonly employed waste materials include fly ash, silica fume, dusts from quarry and fillers and recycled aggregates from construction and demolition waste. Fibres derived from waste include metal fibres from recycled tires, natural fibres from agribusiness and different types of recycled plastics [1,5].

The ever-increasing awareness to provide alternative uses for recycled waste materials, especially in the construction field, pushed forward the idea of making use of one of the most common consumer plastics used - polyethylene terephthalate (PET) - to produce fibres for FRC. This would provide a sustainable alternative for this non-biodegradable material, that of being re-used instead of being taken to recycling facilities for processing.

In Europe alone, more than 60 billion PET bottles were recycled in 2012. More than 52\% of all postconsumer PET bottles were collected for recycling. This collection rate is much higher than the target rate of $22.5 \%$ as stipulated by the waste directive for plastics. This helps recycling plants to work more efficiently and experience a higher utilization rate at their plants. Uses for recycled PET (R-PET) include fibres, which are the largest end-product for such material, used in clothing and textiles industry. RPET is also used for the production of clear sheets and strapping tapes, both used for packaging. In 2008, the passing of EU Regulation 282/2008 on recycled plastic materials and articles intended to come into contact with foods has meant that all EU member states now allow R-PET from approved plants to be used in food contact containers [6] [7]. 
Recycled PET (R-PET) is used for a variety of applications. The clear, higher grade pellets and flakes are primarily used for the food packaging industry whilst flakes which do not make it through the final purification process for food contact, or coloured flakes, find a market in hidden or coloured applications. However, recycling of PET is far from a straight-forward process. Any contamination can result in the downgrading of the material. If materials such as PVC, water, dyes and almost any alien plastic are mixed with PET, they would reduce its properties and quality for certain uses and, to a certain extent, can also make it unusable. Due to the rigorous recycling process that PET has to have, every virgin material experiences a fate known as down-cycling, which results in the plastic being used for lesser quality materials when compared to its original use [8].

Research on the use of R-PET fibres as dispersed reinforcement in concrete and mortars has been ongoing for about a decade with sporadic studies. Ochi et al. [9] also reported a number of applications of R-PET FRC in Japan, including road construction, tunnels, bridge piers and underground storage containers for LNGs.

Ochi et al. [9] and Kim et al. [10] investigated the bond behaviour of R-PET fibres with a concrete matrix, also with reference to the effects of the fibre surface characteristics. Embossed fibres provided the highest bond strength, followed by crimped and straight ones [10]. The effects of fibre surface characteristics on the bond behaviour also resulted in comparable improvement of the resistance to plastic shrinkage cracking, mainly for lower fibre volume fractions. Comparable performance between R-PET and industrially produced polypropylene (PP) fibres was measured, either with reference to bond [9] or with reference to the reduction in the restrained shrinkage cracking potential [10].

As for the effects of the inclusion of R-PET fibres on the compressive strength of R-PET FRC, contradictory results were found in the literature. While Ochi et al. [9] reported a moderate increase of the compressive strength (from 6 to 13\%) for fibre volume fractions up to $1 \%$, the increase diminishing or even turning into a decrease for higher fibre volume ratios, Kim et al. [11] reported a moderate (up to 9\%) decrease. Both studies agree that R-PET FRC features a lower elastic modulus than the reference plain matrix, decreasing with increasing the fibre content.

The difference in results obtained by the two studies can be attributed to the fact that different material processing of the PET fibres affected their intrinsic fibre properties. It is likely that the fibres used by Ochi et al. [9] had a lower elastic modulus, which in turn would have effectively restrained the tensile stresses with little deformation, thus allowing higher compressive loads to be reached. [11] Coherently with the aforementioned assumptions, the highest increases were measured by Ochi et al. [9] for the less strong concretes. 
Pelisser et al. [12] observed that a slight increase in the compressive strength after 28 days took place in the samples having PET fibres whilst a decrease was observed after 150 days, indicating degradation signals of the PET fibres in an alkaline environment, as also confirmed by dedicated studies [13].

With reference to flexural toughness performance, Ochi et al. [9] performed four-point bending test on 100x100x400 mm unnotched prisms. They measured remarkable post-cracking residual strength and toughness increase, with respect to the parent plain matrix, comparable to the one obtainable with other types of industrial fibres [14], as also confirmed by the deflection hardening behaviour obtained for the highest tested R-PET fibre volume fraction $(1.5 \%)$.

These findings were also confirmed by Pelisser et al. [12] who, also with reference to flexural performance, highlighted the detrimental effects of the alkaline environment on the degradation of the PET fibres. As a matter of fact the performance measured 150 days after casting resulted worse than the one at 28 days.

The joint need to providing an effective recycling solution for large quantities of post-consumer waste, such as PET bottles, in an island-state community as Malta, and of confirming and widening the quite scant experimental database available in the literature about the engineering performance of R-PET FRC has motivated the investigation detailed in this paper.

To the authors' knowledge the novelty of this study mainly consists in the following two aspects:

- fibres are obtained by simply and directly shredding the waste plastic bottles with no need for pre-processing the plastic e.g. through melting or heat treatment and subsequent fibre spinning;

- a comprehensive investigation has been herein undertaken, which encompasses and complements the previously cited investigation in a unified framework. As a matter of fact, this study starts with analyzing the properties of the fibres and their bond with the matrix and proceeds going on with the assessment of their effectiveness, as a function of their type and dosage, in mitigating plastic and restrained drying shrinkage cracking. Finally the measurement of the flexural performance of the R-PET FRC according to the most recent international code prescriptions (Model Code 2010, EN 14651) has been performed.

This kind of a thorough investigation hardly could be found in the literature so far, referenced studies dealing with either one or the other single property, and, but for one study [15] on mortar reinforced with R-PET fibres from shredded bottles, all focused on processed PET fiber spinning production.

\section{Experimental programme: materials and testing}




\subsection{Materials}

Two different fibre geometries were employed in this research, straight and deformed. Furthermore, two different fibre lengths were examined, $50 \mathrm{~mm}$ and $30 \mathrm{~mm}$, for each fibre profile.

With these types of fibres, different mixes were prepared, also considering the effects of fibre volume fraction, according to the matrix shown in Table 1. For the preparation of the control and FRC mixes, the materials listed in Table 2 were employed.

Table 1: Tested concrete mixes

Table 2: Materials used

Fibres were obtained from recycled PET bottles, using a mechanical shredder (Figure 1). Bottle segments were first cut in order to be inserted into the shredder. The obtained $2 \mathrm{~mm}$ wide strips were then further cut to the required fibre length using a guillotine cutter.

Figure 1: Mechanical shredder used for the cutting of fibres

The chosen lengths of fibres for this study were $50 \mathrm{~mm}$ and $30 \mathrm{~mm}$ respectively, focusing primarily on the deformed fibres with the purpose of including 3 notches for the longer fibre and 2 notches for the shorter fibre (Figure 2). The notches play a vital role enhancing the effective anchorage of the fibre into the concrete matrix.

Figure 2: Different fibres used (Straight 3cm, Deformed $3 \mathrm{~cm}$, Straight $5 \mathrm{~cm}$, Deformed $5 \mathrm{~cm}$ )

Since both the deformed and straight fibres were derived from beverage plastic bottles, a statistical evaluation of the fibre geometry was necessarily performed. The developed length of both fibre types was determined by measuring 360 random samples of each fibre type using a millimetre rule. A micrometre screw gauge was used to determine the fibre cross sectional area. The statistical data collected from the measurement of the different fibre thicknesses indicate that the thickness for the deformed fibres was $0.205 \mathrm{~mm}$ whilst that of the straight fibres was $0.331 \mathrm{~mm}$, with a coefficient of variation of 0.077 and 0.143 respectively. From the cross-sectional area of each fibre, the equivalent diameter of a circle with an area equal to the mean cross-sectional area of the fibre could be calculated. Finally, the aspect ratio was calculated by dividing the approximate length of the fibre by the equivalent diameter. The estimated aspect ratios for each fibre types are found in Table 3.

Table 3: Fibre aspect ratios 


\subsection{Mixing methodology}

According to the rationale of investigation variables detailed in Table 1, nine different mixes were prepared, with compositions shown in Table 4. The mix composition was designed for an average cube compressive strength equal to $30 \mathrm{~N} / \mathrm{mm}^{2}$ and a target slump of 30 to $60 \mathrm{~mm}$ for fibre reinforced mixes and of $100 \mathrm{~mm}$ for the plain reference control mix. As it clearly appears from the mix compositions detailed in Table 4, all concretes contained the same amount of fine aggregate, cement, water and superplasticizer. The weight proportion of coarse aggregate was reduced by the volumetric replacement of fibres using the relative specific gravities of each material.

Table 4: Mix proportions for the concrete mix variables

All the mixes were prepared using a pan type mixer having a capacity of 60 liters. The required material for each mix were prepared and weighed just before mixing. Batching of all materials was done using a digital scale (to the nearest $\pm 0.5 \mathrm{~g}$ ) to achieve a high degree of accuracy.

Prior to mixing, the pan mixer was buttered with a mixture of sand, cement and water. The mixture was then emptied from the pan and batched materials were added in the pan.

Initially, the fine and coarse aggregate were placed in the pan and mixed for two minutes. Approximately half of the total water was added to the mix and left for 1 minute or until the coarse aggregated fraction was coated by fines. Subsequently, cement was added to the mix together with the rest of the water and the superplasticizer. The latter was mixed to 0.5 litres of water from the original batch to ensure a better distribution in the mixture. All the materials were then further mixed for 4 minutes. When fibres were employed, they were added gradually to the rotating mixer after all the other materials had been mixed for 2 minutes. After all the fibres were added, the concrete was mixed for an additional two minutes.

Where mortar was to be used, the coarse aggregate and its relative water absorption were left out. It is furthermore worth remarking that the proportions of the employed mortar were obtained from the mixdesign of concrete, eliminating the coarse aggregates and scaling up to dosage up to 1 cubic meter.

\subsection{Experimental tests}

\subsubsection{R-PET Fibre tests}

Tensile strength 
The tensile strength and ductility of the recycled fibres was first of all determined, also assessing the variability of the aforementioned properties as affected by different "bottle" sources.

Three samples for each type of fibres were tested. Each fibre was first measured using a micrometer screw gauge and a millimetre rule to determine its cross-sectional area and length. The fibre was then placed in the grips of a $5 \mathrm{kN}$ load cell, maintaining a distance between the grips of $50 \mathrm{~mm}$; load was applied at a rate of $2 \mathrm{~N} / \mathrm{s} .1 \mathrm{~mm}$ thick rubber strips were placed on the inner side of the grips to increase the friction between the fibre and the grips, and to avoid the steel grips to cut through the fibres as they were tightened. The ultimate tensile load was divided by the cross-sectional area to derive the ultimate tensile stress and percentage elongation for each sample.

\section{Pull out}

Cylinder specimens, $200 \mathrm{~mm}$ high and with a diameter equal to $100 \mathrm{~mm}$, were casted for pull out tests. In each cylinder, a fibre was embedded. Three samples from each fibre type were embedded along a length of $10 \mathrm{~mm}$, and another three samples from each fibre type were embedded along a length of $25 \mathrm{~mm}$. In Table 5, a synopsis of the pull-out test variables is provided.

\section{Table 5: Labelling notification for pull-out specimens}

A jig was used to ensure that the fibres were oriented parallel to the pull-out force. The jig consisted of a laser cut $15 \mathrm{~mm}$ thick transparent Poly(methyl methacrylate) rectangular block. The inner circumference of the jig was such that when it was abutted against the cylindrical mould it would position the fibre in the centre of the mould. To ensure that no tensile forces were induced in the fibre during extraction of the jig, it was designed to be snapped off at either side of the embedded fibre.

Figure 3: Schematic design and sample for pull-out test

On the testing day, the samples were glued to a steel plate using 'HILTI, HIT-HY 150 MAX Chemical Anchor'. The steel plate and the sample were then connected by two bolts to the testing rig that was positioned in the jaws of the tensile test machine. The setup (Figure 3) was designed in order to ensure that the forces applied to the fibre would be purely tensile. Due to the tightening mechanism of the jaws, the fibre could not be tightened at its base. A distance of $30 \mathrm{~mm}$ was left between the base of the fibre and the jaws of the machine. The fibre were then loaded in tension at a rate of $2 \mathrm{~N} / \mathrm{s}$ and the applied load together with the machine edge displacement were recorded.

The maximum pull out load could then be used to determine the maximum mechanical bond strength $\tau$ 
using the following formula:

$\tau_{\max }=\mathrm{P}_{\max } / 2(\mathrm{~b}+\mathrm{t}) 1$

Where

$\tau_{\max }$ is the maximum mechanical bond strength of the fibre

$\mathrm{P}_{\max }$ is the maximum pull out load

$\mathrm{b}$ is the fibre width

$\mathrm{t}$ is the fibre thickness

1 is the embedded length of the fibre

\subsubsection{RPET FRC tests}

\subsubsection{Plastic shrinkage}

An environmental chamber was used to investigate plastic shrinkage cracking in a controlled environment. The conditions are similar to those found in the ASTM standard C1579-06 (Standard Test Method for Evaluating Plastic Shrinkage Cracking of Restrained Fiber-Reinforced Concrete) [16].

The chamber (Figures 4-5) consists of half-inch thick chipboard panels, $1460 \mathrm{~mm}$ long by $840 \mathrm{~mm}$ wide by $560 \mathrm{~mm}$ high, providing space for two halogen heaters and an elevated platform to place the concrete specimen mould together with a container filled with a body of water. An industrial high-velocity fan was located outside of the chamber to direct a constant flow of air inside the chamber. A sheet metal form was attached to the chamber to enclose the fan so that wind losses were reduced and air directed into the chamber. This deflector also ensured adequate exit channels which in turn guaranteed the correct circulation of air flow inside the chamber. Another halogen heater was placed behind the high velocity fan to provide pre-heated air into the chamber to assist the other heaters, which together provided the predetermined ambient temperature of approximately $40{ }^{\circ} \mathrm{C} .5 \mathrm{~mm}$-thick perspex panels were used to close the environmental chamber from the top whilst allowing for visual inspection.

Figure 4: Environmental chamber

Figure 5: Environmental chamber setup

A $6 \mathrm{~mm}$ welded metal sheet rectangular mould having internal dimension of $560 \mathrm{~mm}$ length by $355 \mathrm{~mm}$ 
width by $100 \mathrm{~mm}$ depth was used to cast the specimens (Figure 6). Inside, three risers were present; two small ones on the side to provide restraint to shrinkage and one large rise in the centre which reduced the concrete section thickness from $100 \mathrm{~mm}$ to approximately $35 \mathrm{~mm}$, which caused a localized stress zone that induced cracking at that point. $17 \mathrm{~mm}$ bolts were also added at the ends of the specimen mould to provide additional restraints.

Figure 6: Specimen mould dimensions

\section{Test procedure}

The fan and heaters were switched on 30 minutes before mixing each and every mix in order to allow the setup to achieve the desired environmental conditions. Temperature and wind velocity, which were kept constant throughout the duration of the test, were measured by the use of thermocouples and a handheld anemometer respectively. The relative humidity was also measured by a separate data logger.

The ambient and concrete temperatures were measured using two thermocouples connected to a data logger, taking readings every 30 minutes. One thermocouple was attached to the underside of the perspex cover above the specimen whilst the other was inserted into the concrete specimen to a depth of approximately $50 \mathrm{~mm}$, located $100 \mathrm{~mm}$ away from the central riser to avoid disturbance to the crack formation.

The rate of water evaporation was monitored by measuring the loss in weight of water in an open pan having an area equal to $0.1 \mathrm{~m}^{2}$. The pan was placed on a digital scale and logged every 30 minutes in the first 3 hours, and then every hour from the third to the sixth hour. The evaporation from the concrete surface was obtained by dividing the mass loss by the surface exposed to evaporation at the respective time interval.

\section{Plastic shrinkage cracking assessment}

Cracking was monitored by visual inspection every 15 minutes in the first 3 hours after casting and then every hour from the third to the sixth hour, at which time the crack was observed to almost stabilize. The time of occurrence of the first crack was noted for all slabs during the experiments. The specimens were kept in the environmental chamber under controlled humidity conditions until 24 hours after casting.

The specimen was then inspected and photos of the specimen $f$ surface were taken by an optical zoom camera. Magnified images were taken with the use of a USB microscope at 10 different intervals along the length of the crack. A crack microscope was also used to scale a reference point on the concrete specimen. The images taken by the USB microscope were then scaled accordingly with the use of a CAD 
program. After all the photos had been scaled, an average width of the crack could be found.

\subsubsection{Restrained drying shrinkage test (Ring test)}

The setup consisted of an inner steel ring with four eccentric washers to keep it in place whilst casting (Figure 7). An outer PVC ring, also supported by washers, was in place so that the concrete mix could be casted between these two rings. Two strain gauges were glued to the interior wall of the inner ring directly opposite one another at mid-height of the ring. Before casting the concrete, the bottom face was given an epoxy coating so that frictional restraint would be minimized. This all conforms to the ASTM standard C1581 'Standard Test Method for Determining Age at Cracking and Induced Tensile Stress Characteristics of Mortar and Concrete under Restrained Shrinkage' [17].

Concrete was poured in two layers, rodded and vibrated in a circular mould around the steel ring. Once in

place, the eccentric washers were released so that the inner ring was free to move; the strain gauges were connected to the data logger, reading the strains on the steel ring every 15 minutes. The test specimens were cured in the controlled testing environment for 24 hours, after which the outer ring was removed and paraffin wax applied to the top surface of the test specimen so that it was sealed. The ambient temperature and relative humidity of the testing environment was recorded every day, and kept at $22 \pm 2{ }^{\circ} \mathrm{C}$ and $52 \pm 2 \%$, respectively. The test specimen was visually inspected for cracking every day. Cracking of the test specimen was usually noticed by a sudden decrease in the steel ring strain readings.

Figure 7: Casted ring specimen

\subsubsection{Compressive strength}

Three 150x150x150mm cubes per each mix were tested on the 3rd, 7th and 28th day from casting. The test was conducted in accordance with MSA EN 12390-3:2002 [18].

The cubes were placed in a curing tank at a controlled temperature of $21{ }^{\circ} \mathrm{C}$ until the day of testing. On the day of testing, the three cubes were removed from the curing tanks, wiped and cleaned, measured and weighed. These were then placed in the compression machine, with the rough face facing outwards and load was applied at a rate of $0.6 \mathrm{MPa} / \mathrm{s}$ until failure. Each cube was visually inspected and any abnormal failure of the cubes was noted 


\subsubsection{Flexural strength}

A three-point bending rig was setup (Figure 8 a-c) to allow the use of a manually controlled hydraulic pump, applying a centre-point load on a simply supported notched prism. A $5 \mathrm{~mm}$ wide and $25 \mathrm{~mm}$ deep notch was cut at mid-span through the width of the bottom part of the prism. A CMOD transducer, connected to a data logger, was used to measure the crack width at the mid-span notch of the prism. It was slotted into the centre of the notch. Two LVDTs, connected to the data logger, were also used to measure the mid-span deflection. These were placed on the top of the top roller. The tests were performed, according with EN 14651:2005 [19] and were carried out on the 28th day from casting; until testing the specimens were cured as cube specimens for compressive tests.

The tests were performed controlling the actuator displacement which was increased at a rate of 0.08 $\mathrm{mm} / \mathrm{min}$ up to $1 \mathrm{~mm}$ crack opening and at a rate of $0.21 \mathrm{~mm} / \mathrm{min}$ afterwards. The test was terminated once the CMOD transducer reached its $5 \mathrm{~mm}$ crack width limit.

Figure 8 a-c: Flexural test setup, LVDTs and crack transducer

\subsubsection{Mortar shrinkage}

These tests were conducted to assess the cracking potential of fibre-reinforced mortar mixes in thin slabs, according to the set-up proposed by Kraai [20].

The mould (Figure 9a) consisted of a $610 \times 914 \mathrm{~mm}$ panel $19 \mathrm{~mm}$ deep. It was constructed using plywood sheets which were glued and nailed together. The inside faces of the mould were covered with polythene sheeting so as to prevent absorption of water by the plywood and also prevent the restraining of mortar during shrinkage.

A wire steel mesh was used for perimeter restraints, provided at $12.7 \mathrm{~mm}$ intervals (Figure $9 \mathrm{~b}$ ). The mesh was bent at right angles so as to project $13 \mathrm{~mm}$ into the mortar and connected to the mould base via pins.

Figure 9a: Kraai panel

Figure 9b: Steel mesh perimeter restraint

\section{Test procedure}

A 20 liters pan mixer was used to mix the mortar. The same mix design was kept as for the concrete mix, only removing the coarse aggregate fraction and not accounting for its relative water absorption. Once the mortar was mixed sufficiently, it was poured into the plywood mould, vibrated and trowelled so as to 
achieve a smooth finish. Thereupon, the mould was carefully moved to a controlled environment at a temperature of $22 \pm 2{ }^{\circ} \mathrm{C}$ and relative humidity of $50 \pm 2 \%$. To further induce cracking, the specimen was exposed to a wind speed of $6 \mathrm{~m} / \mathrm{s}$, generated by means of an industrial fan for the first 5 hours. Wind speed was monitored by a handheld anemometer (Figure 10).

Figure 10: Kraai panels exposed to wind load

Evaluation of panels was carried out 24 hours after casting. Crack lengths and average crack width were recorded for each specimen. Crack widths were divided into four categories, each of which was assigned a weighted value as shown in Table 6. For each crack, the weighted value is multiplied by the crack length in mm to obtain the 'average weighted value'. The sum of the weighted average values of all the cracks in a panel, called the 'total weighted average value', was used as a comparative measure of the specimen's crack potential. Table 7 shows the different fibre mortar mixes investigated.

Table 6: Crack weighting

Table 7: Mortar mix variables

\section{Experimental results}

\subsection{Tensile tests on R-PET fibres}

The two fibre types behaved in a similar manner. Upon loading, the PET behaved elastically until the yield point was reached. Beyond this point, the fibres continued to resist load, displaying increasing degrees of extension, until failure.

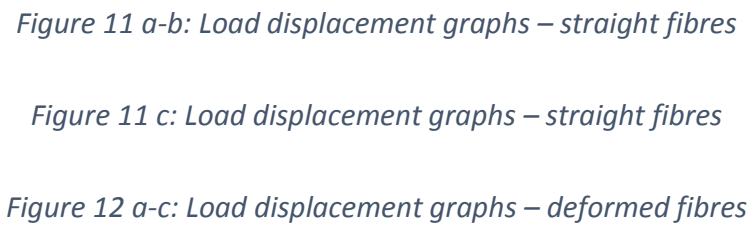

Figures 11 and 12 a-c show that the fibres behaved elastically in the initial stages of loading until the elastic limit was reached. Up until this point, the percentage elongation was approximately $3.5 \%$ and 9.5\%, of the straight and deformed fibres, respectively. Beyond this point, the fibres continued to resist load up to an ultimate load of approximately $110 \mathrm{MPa}$, where the percentage extension reached values of higher than $80 \%$. 
In the deformed fibres, the higher elongation can be partially attributed to the initial straightening of the notches, as can be noted by the initial behaviour of the graphs in Figure 12 a-c [21].

\subsection{Pull out test}

Observations were made regarding the deformation of the fibres upon pull-out. As a result of the setup limitations, the displacement values measured include the extension of the fibre due to strain. However, from the shape and nature of inconsistencies in the curve, points of slip can be clearly identified.

\subsubsection{Straight fibres $-10 \mathrm{~mm}$ embedded length}

As the three samples as detailed in Table 8 were loaded, the imparted strain caused the section of the fibre above the embedded length to extend. This continued until the peak load of each sample was reached. At this point, the fibres de-bonded from the concrete matrix and pull out occurred (Figure 13). In all the samples, pull out occurred within the elastic deformation limits of the fibres. When observing the surface of the fibre under a microscope, fine abrasions due to surface scratching was observed.

Table 8: Mechanical bond characteristics - Straight fibres

Figure 13: Load displacement curve of sample S10-A

\subsubsection{Deformed fibres $-10 \mathrm{~mm}$ embedded length}

All three samples reached their ultimate load before failure occurred. Although pull out did not occur, there were several points of sudden deflection within the load displacement curve, at these points, the fibre partially slipped within the matrix, but was still capable of taking more load (Figure 14). Because complete pull-out of the fibres did not occur it was only possible to determine a value above which the mechanical bond strength is expected to fall, and not the mean bond strength.

Table 9: Mechanical bond characteristics - Deformed fibres

Figure 14: Load displacement graph of sample D10-A

\subsection{3. $25 \mathrm{~mm}$ embedded length fibres}

The straight fibre samples, as shown in Figure 15 a-c, still failed by pull-out, further confirming the poor bond characteristics obtained from the $10 \mathrm{~mm}$ embedded length tests. The deformed fibres achieved their ultimate load, and failed by yielding. As can be observed in Figures 16 a-c, no slip occurred at any point during the tests [22]. 
Figure $15 a$-b: Load displacement graphs - 25mm straight fibres

Figure 15 c: Load displacement graphs - 25mm straight fibres

Figure 16 a-c: Load displacement graphs $-25 \mathrm{~mm}$ deformed fibres

\subsection{Compressive strength}

For each concrete mix, three $150 \mathrm{~mm}$ cubes were tested at the $3 \mathrm{rd}, 7$ th and 28 th day from casting. The mean compression strength values for each testing age are shown in Figure 17.

Figure 17: Cube compression results

The addition of recycled PET fibres had no beneficial effect on the compressive strength of the concrete mix. A strength reduction ranging from $0.5 \%$ to $8.5 \%$ was observed for both fibre types when compared to the control mix.

Upon increasing fibre volume fraction, there is a slight decrease in compressive strength (more likely because of a steric disturbance effect) which is more pronounced for the highest dosage of the longest deformed fibres (strongest disturbance effect). The effect of fibre length is not significant at all.

Straight fibres showed a stronger reduction for the lowest dosage and no further significant variation upon further increasing the fibres, whilst deformed fibres showed no initial appreciable decrease and a stronger one only for highest dosage.

Figures 18 a-b show an example of cube specimens after failure: the achieved good dispersion of fibers is highlighted.

Results are qualitatively and quantitatively coherent with the ones from previous investigations [11] [22].

Figure 18a: Deformed fibre-reinforced cube after failure Figure 18b: Straight-fibre reinforced cube after failure

\subsection{Flexural tests}

\subsubsection{Flexural strength behaviour}

Three 150x150x550 mm prisms were tested for each mix as per EN 14651:2005 [19]. The graphs in 
Figure 19-20 show the average relationship between load and CMOD for deformed and straight R-PET FRC mixes respectively.

Effect of fibre profile \& volume

Figure 19: Flexural behaviour of deformed fibre reinforced prisms

It was observed that the control mix specimens failed instantaneously after reaching peak load splitting into two halves. The crack width readings were marginally small when compared to the fibrous specimens.

The prisms containing deformed fibres all exhibited similar behaviour. The cracks all developed at the centre through the notch as soon as the peak load was reached. The specimens containing $1 \%$ fibre volume achieved the highest flexural strength, whilst those containing the highest fibre volume fraction exhibited the highest residual strength.

Figure 20: Flexural behaviour of straight fibre reinforced prisms

The same behaviour was observed in the prisms containing straight fibres, with reference to both the peak load and at the post-crack residual strength, at least in the initial stage. However, the residual strength phase is characterized by a slight "pseudo hardening" which can be correlated to the progressive activation of the fibres.

Upon the attainment of quite large crack opening displacement values (of around $3 \mathrm{~mm}$ ), the residual strength capacity also started to decrease.

\section{Effect of fibre length}

Figure 21 shows the relationship between the load and crack width for different fibre types and lengths at $1 \%$ volume fraction. Deformed fibres had a slightly better performance than straight fibres whilst longer fibres performed better than their shorter counterpart. The effect of fibre length is higher than the effect of fibre type.

Figure 21: Flexural behaviour of different fibre type and lengths

\section{Effect of fibre profile on bond strength}

The cross-section of each prism was inspected after loading. Specimen with deformed fibres were noted to have fibres at either end of the crack which matched to one another, implying the fibres failed by yielding instead of pull out. This also shows that the deformed fibres provided a sufficient mechanical 
bond with the matrix to resist the tensile strength imposed on the prism. On the other hand, it was noted that some of the prisms containing straight fibres had fibres on one side only, implying that pull-out occurred. This means that the fibres slipped from the matrix.

Results obtained in this study are absolutely coherent with the ones available in the literature [9, 22]. The mechanical performance obtained with recycled PET fibres has a trend which is coherent with the one obtained employing industrial polymeric fibres [14].

\subsubsection{LOP and residual strength}

From the load vs. CMOD response, as shown in Figure 13-15, the limit of proportionality and nominal flexural residual strengths at prescribed CMOD values were calculated as per EN 14651 [19].

It is worth remarking that because of the unstable response exhibited by all the specimens after first cracking and up to a CMOD value roughly equal to $1 \mathrm{~mm}$, the residual strength denoted in EN 14651 as $f_{R 1}$ (corresponding to a CMOD value equal to 0.5 ) was not calculated. Other $f_{R j}$ values, in correspondence of CMOD values respectively equal to $1.5,2.5$ and $3.5 \mathrm{~mm}$ were calculated and are shown, together with the proportionality limit, in Figure 22.

Figure 22: LOP \& residual flexural tensile strength

\subsubsection{Peak load behaviour}

Fibres increased a little the flexural strength (for higher dosages there is an increase of about 20\%) but with no significant difference between the two types of fibres. Longer fibres always perform slightly better than shorter ones, mainly for deformed fibres. $1 \%$ fibre volume seems to be a saturation dosage for improving flexural strength as higher dosages could be even worsening because of steric disturbance.

\subsubsection{Residual strength behaviour}

Residual strengths increase with increasing fibre volume percentage. Due to the measured behaviour (almost flat post cracking response in the CMOD ranges of interest) the values of different $\mathrm{f}_{\mathrm{rj}} \mathrm{s}$ are not that much different. Deformed fibres provided a 10 to $20 \%$ higher residual strength values than straight ones whilst short fibres performed quite poorer than longer ones. Better bond is the reason behind the better performance of longer deformed fibres than their respective counterparts.

\subsection{Plastic shrinkage}




\subsubsection{Rate of evaporation}

Figure 23: Rate of evaporation

Figure 23 shows the average rate of evaporation for all the performed tests and also indicates that the rate

of evaporation of $1 \mathrm{~kg} / \mathrm{m}^{2} / \mathrm{hr}$ has been achieved after about 5 hours from the test beginning. This rate is deemed critical by some codes whereas others recommend lower values. In this study, it was observed that even though the critical limit was achieved at a later stage in the test, cracking still occurred at an earlier stage [23-25].

\subsubsection{Time of crack formation}

Figure 24: Time of first crack formation

The graph in Figure 24 shows the time of first crack formation of each mix. The control mix and S5-0.5 mix were the first to suffer from concrete surface cracks at a time of 1 hour and 30 minutes. The deformed fibres performed better in delaying crack formation by about 15 minutes. It was also observed that the crack formation was also delayed by higher volume fractions in the mix in both fibre types. The shorter fibres performed worse than the longer ones and, as in both fibre types, the initial crack formed earlier.

\subsubsection{Concrete temperature}

\section{Figure 25: Concrete specimens temperature}

The concrete temperature is one of the contributing factor in the rate of evaporation and subsequent plastic shrinkage cracking. The internal concrete temperature readings were measured at a depth of 50 $\mathrm{mm}$ within the concrete. Figure 25 shows the almost linear increasing temperature for the first 6 hours, having an initial temperature ranging between $22-28{ }^{\circ} \mathrm{C}$ and an increase of between $9-18{ }^{\circ} \mathrm{C}$ at the end of the test. A slight increase in the rate of evaporation was observed in the last hour, in mixes containing high fibre volume fractions.

\subsubsection{Plastic shrinkage cracking}

Figure 26: Relationship between fibre volume fraction and crack width 
Figure 26 shows the relationship between different fibre volume fractions and related crack widths. Deformed fibres, even at $0.5 \%$ by volume, were able to reduce cracks by $37.8 \%$ with respect to the control mix. As the deformed fibre volume increased to $1 \%$ and $1.5 \%$, the percentage reduction from the control mix was that of $60.4 \%$ and $68.7 \%$, respectively.

The straight fibres performed slightly less efficiently in restraining the crack development. The behaviour was noted to be similar to the deformed fibre prisms, however, the mean crack widths were slightly larger and the difference increased as the fibre volume fraction increased. When compared to the control mix, a reduction of $33.1 \%, 54.9 \%$ and $60.6 \%$ was observed at fibre volume fractions of $0.5 \%, 1 \%$ and $1.5 \%$, respectively.

With reference to the effects of fibre length, it can be observed from the bar chart in Figure 27, that the performance of shorter fibres was quite poorer than that of deformed ones, because of the poorer bond. This is also witnessed by the performance difference for straight short fibres, which is about $60 \%$ lower than that of longer ones, whereas for deformed fibres such difference is less dramatic.

Figure 27: Relationship between fibre length and crack width

The straight fibres showed the greatest difference in crack width, with an increase of $65.8 \%$ when compared to the result of the longer fibres, whilst the deformed fibres showed an increase of $27.1 \%$.

Results are qualitatively and quantitatively coherent with previous investigations by Naaman et al., with reference to fibre volume fraction and fibre profile type [26].

\subsection{Restrained shrinkage}

Figure 28: Compressive strain imposed on the ring against time duration

As from the measurements of the steel annulus hoop strains (Figure 28) it can be observed that the control mix reached its peak stress of 60 micro strains at 12 days from casting, after which it suffered from a series of micro cracks before suffering a sudden drop in stress of about 40 micro strains. A crack was visually noticed at that time, shown in Figures 29 a-b.

\section{Figure 29a: CM ring specimen Figure 29b: CM ring test crack}

The D5-0.5 specimen reached its peak strain at 18 days from casting, after which a drop in the strains was measured along the steel annulus caused by an evident crack in the specimen. The fibres added into the mix, due to their low quantity, were not able to resist the development of the crack (Figures $30 \mathrm{a}-\mathrm{b}$ ). 
The other two mixes (D3-1 and D5-1) showed different behaviour after reaching peak stress. The D3-1 specimen, containing $1 \% 30 \mathrm{~mm}$ long deformed fibres, reached the peak at 17 days from casting, however there wasn't a sudden drop. Instead, the strain was noted to reduce gradually, one strain gage effectively showing the reduction of strain more than the other, likely due to one of the strain gages being directly opposite the crack. The crack was observed at naked eye three days later, when a difference of 60 micro strains has been recorded. This behaviour is attributed to stress relaxation due to the fibres present in the mix.

The D5-1 specimen, containing $1 \%$ by volume $50 \mathrm{~mm}$ long deformed fibres, reached its peak stress after only 10 days and the strain value reached was low when compared to the other mixes. However, the strain started to decline really slowly and even though it is likely that a number of internal micro-cracks may have developed, no cracks were visually noticed after 28 days from casting. This behaviour is linked to stress relaxation and it can be concluded that at such fibre volume, the fibres were able to provide enough stress resistance to resist crack formations.

\section{Comparison with literature}

Shah and Weiss [27] observed that at low volume fractions, fibres do not alter the strains prior to cracking, however they can alter the behaviour after the crack has formed, resulting in a greater amount of strain transfer across the crack and small crack widths. Even though the specimen containing low fibre volume fractions (D5-0.5) took longer to crack, it also achieved a greater strain prior to cracking, when compared to the control specimen.

The authors also observed that specimens containing high volume of fibres permit higher strains before a visible crack develops, however small decreases in strain can be observed before visible cracking occurs.

When comparing the specimens in this study containing high fibre volume fractions, both specimens showed low decreases in strain, as observed in the literature, with the D3-1 specimen developing a crack after 3 days from achieving the highest strains whereas the D5-1 specimen did not crack after 28 days. It was observed that the one containing the shorter fibres managed to achieve higher strains than the specimen containing the longer fibres [27].

This is also coherent with the results by Voigt et al. [28], who observed that cracking age increased whilst maximum crack width decreased with increasing fibre volume in all types of fibres. The authors also observed that increasing the number of fibres per unit volume resulted into an increased cracking age $[20]$. 


\subsection{Kraai test}

\subsubsection{Effect of fibre profile and volume}

Figure 31: Relationship between crack area and fibre volume fractions

The graph in Figure 31 shows the effect of inclusion of fibres at increasing fibre volume fractions. A similar reduction in crack area was observed for both fibre types, with the deformed fibres performing slightly better than straight ones, especially at lower fibre volumes. Both fibre types provided an increase in crack reduction with increasing the fibre volume fractions. The highest reduction difference was observed for a fibre volume fraction of $0.5 \%$. The least amount of cracks was observed in the panel containing $1 \%$ by volume $50 \mathrm{~mm}$ long deformed fibres, with a reduction of $92.6 \%$, when compared to the control mix.

\subsubsection{Effect of fibre length}

Figure 32: Relationship between crack area, fibre type and length

The graph in Figure 32 shows the effect of fibre length on crack reduction. It was observed that the longer fibres performed better in both fibre types. There was a slight increase of $17 \%$ in crack formation in the deformed short fibre panel when compared to the panel with the longer fibres. However, a larger difference was noted with the use of $30 \mathrm{~mm}$ straight fibres. There was an increase of $60 \%$ in crack area when compared to the panel containing the longer straight fibres. As described earlier, the shorter fibres have less anchorage than the longer fibres and, coupled also with a smaller aspect ratio, they performed less efficiently than the longer fibres.

\subsubsection{Crack pattern}

By observing the crack pattern formed on the mortar panels (Figure 33), a difference can be observed with different fibre volumes. As the fibre volume fraction increased, a reduction in the amount of cracks on the surface could be noticed. Maximum crack widths of $3 \mathrm{~mm}$ were measured on the control and low volume fibre fraction panels, whilst those containing $1 \%$ fibre volume had only a couple of hairline cracks. 
Figure 33b: Kraai mix variables panels - crack pattern

Results obtained in this study are absolutely coherent with the ones available in the literature by Schembri [22]. Kim et al. [10] observed little additional effects beyond the $0.5 \%$ fibre volume fraction.

\section{Conclusions}

The purpose of this study was to investigate the use of recycled PET fibres, both straight and deformed, in concrete as a waste material by assessing their effect on mechanical properties and early age performance in concrete specimens. Nine mixes were tested with two different fibre profiles at three different volume fractions and two different fibre lengths at a particular volume fraction and the feasibility of using RPET fibres as reinforcement in concrete was successfully assessed, also highlighting the effects of fiber surface finishing and length.

From the obtained results the following conclusions can be drawn:

- The addition of recycled PET fibres leads to a reduction of between 0.5 and $8.5 \%$ in compressive strength when compared to the control mix. A higher decrease in strength was observed in both fibre profiles at increasing fibre volume fractions. Cubes containing shorter fibres performed slightly better when compared to those containing longer fibres. The D5-1.5 suffered the greatest reduction in strength, attributable to low workability and poor compaction.

- Results from the flexural tests show that the concretes containing fibres achieved a higher peak load than the control mix. All the tested concretes had similar linear elastic behaviour until failure, at which point a sudden loss in strength was observed. Post-crack residual strength was dependent on the fibre volume fraction, with the higher fibre volumes providing the better residual strength. The deformed fibres provided better residual strengths due to a better bond, reflected in the fibre failing by yielding, as opposed to the straight fibres, some of which failed by pullout. Concrete mixes containing the shorter fibres achieved a slightly lower peak load when compared to the other mixes; also a slight reduction in post-crack residual strength was observed, attributable to the low bond strength and aspect ratio of the shorter fibres

- An environmental chamber was used to expose a concrete specimen to a set of environmental conditions, so as to induce plastic shrinkage cracking. An assessment performed 24 hours after test commencement, on the crack widths developed showed that even at low fibre volume fractions, the R-PET fibres managed to restrain crack development. The smallest crack width was observed in the mix containing the highest amount $(1.5 \%$ by volume) of $50 \mathrm{~mm}$ long deformed fibres, featuring a $68.7 \%$ reduction with respect to the control mix. Longer fibres were found to be more effective, with the deformed fibres performing slightly better than their straight counterparts in restraining crack 
development, both observations being attributed to the better anchorage in the concrete matrix.

- Mortar panels investigating the same effect as the previous experiment were performed in accordance with the test set-up by Kraai. A similar reduction in total crack area was observed in both fibre types with an increase in fibre volume fractions, with the deformed fibres performing slightly better. The greatest reduction difference was observed up to a fibre volume fraction of $0.5 \%$. A maximum reduction of $92.6 \%$ was observed in the panel cast with a mortar reinforced with $1 \%$ by volume $50 \mathrm{~mm}$ long deformed fibres, when compared to the control mix. Longer fibres performed better than their shorter counterparts, as observed in the other tests. With an increase in fibre volume fraction, the maximum crack widths were observed to undergo a reduction from $3 \mathrm{~mm}$ for the control mix to hairline cracks wide less than $0.5 \mathrm{~mm}$ for the panel cast with a mortar reinforced with $1 \%$ by volume $50 \mathrm{~mm}$ long deformed fibres.

- With reference to restrained shrinkage cracking, the mix reinforced with $1 \%$ by volume of $50 \mathrm{~mm}$ long deformed fibres exhibited the best performance as no cracks were observed after 28 days. Both the control mix and mix reinforced with $0.5 \%$ by volume of $50 \mathrm{~mm}$ long deformed fibres showed a sudden drop in hoop steel ring strains before crack was visually observed on the surface of the concrete ring. Both specimens reinforced with $1 \%$ by volume of $50 \mathrm{~mm}$ and $30 \mathrm{~mm}$ long deformed fibres, did not show this sudden drop in the measured steel annulus strain but rather a slow decrease in strain indicating stress relaxation.

\section{References}

1. Silva, F. de A., Chawla, N. \& Toledo Filho, R.D. (2008). Tensile behavior of high performance natural (sisal) fibers, Composites Science and Technology, 68, 3438-3443.

2. Silva, F. de A., Mobasher, B. \& Toledo Filho, R.D. (2009). Cracking mechanisms in durable sisal fiber reinforced cement composites, Cement and Concrete Composites, 31, 721-730.

3. Silva, F. de A., Chawla, N. \& Toledo Filho, R.D. (2010). Mechanical behaviour of natural sisal fibers, Journal of Biobased Materials and Bioenergy, 4, 1-8.

4. Martinelli, E., Caggiano, A. \& Xargay, H. (2015). An experimental study on the post-cracking behaviour of hybrid/industrial steel fibre-reinforced concrete. Construction and Building Materials, 94, 290.298 .

5. Caggiano, A., Xargay, H., Folino, P. \& Martinelli, E. (2015). Experimental and numerical 
characterization of the bond behavior of steel fibres recovered from waste tires embedded in cementitious matrices. Cement and Concrete Composites, 62, 146-155.

6. Plasticsnews.com. (2014, April). Retrieved from Plasticsnews.com:

http://www.plasticsnews.com/article/20130813/NEWS/130819981/europe-recycled-60-billion-petbottles-in-2012

7. Uses for Recycled PET. (2014, April). Retrieved from Petcore Europe: http://www.petcoreeurope.org/index.php?q=content/uses-recycled-pet-petcore-column-petplanet

8. Ashby, M., Shercliff, H., \& Cebon, D. (2007). Materials: Engineering science processing and design. Elsevier.

9. Ochi, T., Okubo, S., \& Fukui, K. (2007). Development of recycled PET fiber and its applications as concrete-reinforcing fiber. Cement \& Concrete Composites 29, 448-455.

10. Kim, J., Park, C., Lee, S., \& Won, J. (2008). Effects of the geometry of recycled PET fiber reinforcement on shrinkage cracking of cement based composites. Composites, 442-450.

11. Kim, S., Yi, N., Kim, H., Kim, J., \& Song, Y. (2010). Material and structural performance evaluation of recycled PET fiber reinforced concrete. Cement \& Concrete Composites, 232-240.

12. Pelisser, F., Montedo, O., Gleize, P., \& Roman, H. (2012). Mechanical properties of recycled PET fibers in concrete. Materials Research, 679-686.

13. Silva, D. A., Betioli, A. M., Gleize, P. J. P., Roman, H. R., Gomez, L. A., Ribeiro, J. L. D. (2005) Degredation of recycled PET fibres in Portland cement-based materials. Cement and Concrete Research Vol. 35 Issue 9, 1741-1746.

14. Buratti, N., Mazzotti, C., \& Savoia, M. (2011). Post-cracking behaviour of steel and macro-synthetic fibre-reinforced concretes. Construction and building materials 25, 2713-722.

15. Pereira De Oliveira, L.A., Castro-Gomes, J.P. (2011). Physical and mechanical behavior of recycled PET fiber reinforced mortar. Construction and Building Materials, 25, 1712-1717.

16. ASTM C1579-06. (2006). Standard test Method for Evaluating Plastic Shrinkage Cracking of Restrained FIbre Reinforced Concrete.

17. ASTM C1581. (2004). Standard Test Method for Determining Age at Cracking and Induced Tensile Stress Characteristics of Mortar and Concrete under Restrained Shrinkage.

18. EN 12390-3. (2002). Testing hardened concrete. Compressive strength of test specimens. 
19. EN 14651. (2005). Test method for metallic fibered concrete.

20. Kraai, P. (1985). A proposed test to determine the cracking potential due to drying shrinkage of concrete. San Jose State University.

21. Baldacchino, O. (2014). Mechanical and shrinkage properties of recycled PET fibre-reinforced concrete. University of Malta. Supervised by Dr.Ruben Paul Borg

22. Schembri, J. (2011). Recycled Polyethylene Terephthalate fibres in concrete. University of Malta. Supervised by Dr. Ruben Paul Borg

23. ACI Committee 305. (2010). Guide to Hot Weather Concrete ACI 305R. American Concrete Institute.

24. Uno, J. (1998). Plastic Shrinkage Cracking and Evaporation Formulas. American Concrete Institute Materials Journal, Vol.95 No.4, 365-375.

25. Lerch, W. Plastic Shrinkage, ACI J. 53 (1957) 797-802

26. Naaman, A. E., Wongtanakitcharoen, T. \& Hauser, G. (2005). Influence of different fibers on plastic shrinkage cracking of concrete. ACI Materials Journal, 102, 49-58.

27. Shah, H., \& Weiss, J. (2006). Quantifying Shrinkage Cracking in Fiber Reinforced Concrete using the Ring test. Materials and Structures 39, 887-899.

28. Voigt, T., Bui, V. K. \& Shah, S. P. Drying Shrinkage of Concrete Reinforced with Fibers and Welded-Wire Fabric. ACI Materials Journal, 101, 232-241. 


\title{
Early Age Performance and Mechanical Characteristics of Recycled PET Fibre Reinforced Concrete
}

\author{
Ruben Paul Borg ${ }^{1}$, Owen Baldacchino ${ }^{1}$, Liberato Ferrara ${ }^{2}$ \\ ${ }^{I}$ Faculty for the Built Environment, University of Malta, Tal-Qroqq, Msida MSD 2080, Malta, \\ ruben.p.borg@um.edu.mt \\ ${ }^{2}$ Department of Civil and Environmental Engineering, Politencio di Milano, Piazza leonardo da Vinci, Milano, \\ Italy, liberato.ferrara@polimi.it
}

\begin{tabular}{|c|c|c|c|c|}
\hline Mix No. & Description & Fibre Length & Volume Percentage & Name \\
\hline 1 & Control mix & - & $0 \%$ & $\mathrm{CM}$ \\
\hline 2 & \multirow{4}{*}{ Straight Fibre } & \multirow{3}{*}{$50 \mathrm{~mm}$} & $0.5 \%$ & S5-0.5 \\
\hline 3 & & & $1 \%$ & S5-1 \\
\hline 4 & & & $1.5 \%$ & S5-1.5 \\
\hline 5 & & $30 \mathrm{~mm}$ & $1 \%$ & S3-1 \\
\hline 6 & \multirow{4}{*}{ Deformed } & \multirow{3}{*}{$50 \mathrm{~mm}$} & $0.5 \%$ & D5-0.5 \\
\hline 7 & & & $1 \%$ & D5-1 \\
\hline 8 & & & $1.5 \%$ & D5-1.5 \\
\hline 9 & & $30 \mathrm{~mm}$ & $1 \%$ & $\overline{\mathrm{D} 3-1}$ \\
\hline
\end{tabular}

Table 1: Tested concrete mixes

\begin{tabular}{|l|l|}
\hline Cement & $\begin{array}{l}\text { CEM II / A-LL 42.5 R Ordinary Portland Cement } \\
\text { Clinker content }-80-94 \%\end{array}$ \\
\hline Coarse aggregate & $\begin{array}{l}\text { Maltese derived good quality upper coralline limestone } \\
\text { Maximum aggregate size }-12.5 \mathrm{~mm} \\
\text { Water absorption }-1.92 \%\end{array}$ \\
\hline Fine aggregate & $\begin{array}{l}\text { Water absorption }-2.13 \% \\
\text { Maximum aggregate size }-5 \mathrm{~mm}\end{array}$ \\
\hline Chemical admixture & $\begin{array}{l}\text { Glenium } 27, \text { produced by BASF Construction Chemicals } \\
\text { Mix rate: } 1 \mathrm{~kg} \text { of admixture for } 100 \mathrm{~kg} \text { of cement }\end{array}$ \\
\hline
\end{tabular}

Table 2: Materials used

\begin{tabular}{|c|c|c|}
\hline Fibre length / profile & Straight & Deformed \\
\hline $\mathbf{3 0 m m}$ & 33 & 42 \\
\hline $\mathbf{5 0 m m}$ & 55 & 70 \\
\hline
\end{tabular}

Table 3: Fibre aspect ratios 


\begin{tabular}{|l|l|c|c|c|c|c|c|c|c|c|}
\hline Mix & & Control & S5-0.5 & S5-1 & S5-1.5 & S3-1 & D5-0.5 & D5-1 & D5-1.5 & D3-1 \\
\hline Fibre Type & & & $\mathrm{S}$ & $\mathrm{S}$ & $\mathrm{S}$ & $\mathrm{S}$ & $\mathrm{D}$ & $\mathrm{D}$ & $\mathrm{D}$ & $\mathrm{D}$ \\
\hline Fibre Length & $\mathrm{mm}$ & - & 50 & 50 & 50 & 30 & 50 & 50 & 50 & 30 \\
\hline Volume Fraction & $\%$ & 0.0 & 0.5 & 1.0 & 1.5 & 1.0 & 0.5 & 1.0 & 1.5 & 1.0 \\
\hline W/C & & 0.55 & 0.55 & 0.55 & 0.55 & 0.55 & 0.55 & 0.55 & 0.55 & 0.55 \\
\hline & & & & & & & & & & \\
\hline Cement & $\mathrm{kg} / \mathrm{m}^{3}$ & 409 & 409 & 409 & 409 & 409 & 409 & 409 & 409 & 409 \\
\hline Water & $\mathrm{kg} / \mathrm{m}^{3}$ & 225 & 225 & 225 & 225 & 225 & 225 & 225 & 225 & 225 \\
\hline Fine Aggregate & $\mathrm{kg} / \mathrm{m}^{3}$ & 900 & 900 & 900 & 900 & 900 & 900 & 900 & 900 & 900 \\
\hline Coarse Aggregate $\mathbf{( 1 2 . 5 m m )}$ & $\mathrm{kg} / \mathrm{m}^{3}$ & 736 & 723.3 & 710.6 & 697.9 & 710.6 & 723.3 & 710.6 & 697.9 & 710.6 \\
\hline Superplasticiser & $\mathrm{kg} / \mathrm{m}^{3}$ & 4.09 & 4.09 & 4.09 & 4.09 & 4.09 & 4.09 & 4.09 & 4.09 & 4.09 \\
\hline Water absorption $\mathbf{( 2 4 h r )}$ & $\mathrm{kg} / \mathrm{m}^{3}$ & 33.30 & 33.06 & 32.81 & 32.57 & 32.81 & 33.06 & 32.81 & 32.57 & 32.81 \\
\hline
\end{tabular}

Table 4: Mix proportions for the concrete mix variables

\begin{tabular}{|c|c|c|}
\hline Fibre type & Embedded length (mm) & Sample name \\
\hline \multirow{6}{*}{ Straight } & \multirow{3}{*}{10} & S10-A \\
\hline & & S10-B \\
\hline & & S10-C \\
\hline & \multirow{3}{*}{25} & S25-A \\
\hline & & S25-B \\
\hline & & S25-C \\
\hline \multirow{6}{*}{ Deformed } & \multirow{3}{*}{10} & D10-A \\
\hline & & D10-B \\
\hline & & D10-C \\
\hline & \multirow{3}{*}{25} & D25-A \\
\hline & & D25-B \\
\hline & & $\mathrm{D} 25-\mathrm{C}$ \\
\hline
\end{tabular}

Table 5: Labelling notification for pull-out specimens

\begin{tabular}{|c|c|}
\hline Crack width & Weighted value \\
\hline Large (about $3 \mathrm{~mm}$ ) & 3 \\
Medium (about $2 \mathrm{~mm}$ ) & 2 \\
Small (about $1 \mathrm{~mm}$ ) & 1 \\
Hairline (about $0.5 \mathrm{~mm}$ ) & 0.5 \\
\hline
\end{tabular}




\begin{tabular}{|c|c|c|c|c|}
\hline Mix No. & Description & Fibre Length & Volume Percentage & Name \\
\hline 1 & Control Mortar mix & - & $0 \%$ & CMM \\
\hline 2 & \multirow{5}{*}{$\begin{array}{l}\text { Straight Fibre } \\
\text { Reinforced Mortar }\end{array}$} & \multirow{4}{*}{$50 \mathrm{~mm}$} & $0.25 \%$ & SM5-0.25 \\
\hline 3 & & & $0.5 \%$ & SM5-0.5 \\
\hline 4 & & & $0.75 \%$ & SM5-0.75 \\
\hline 5 & & & $1 \%$ & SM5-1 \\
\hline 6 & & $30 \mathrm{~mm}$ & $1 \%$ & SM3-1 \\
\hline 7 & \multirow{5}{*}{$\begin{array}{l}\text { Deformed Fibre } \\
\text { Reinforced Mortar }\end{array}$} & \multirow{4}{*}{$50 \mathrm{~mm}$} & $0.25 \%$ & DM5-0.25 \\
\hline 8 & & & $0.5 \%$ & DM5-0.5 \\
\hline 9 & & & $0.75 \%$ & DM5-0.75 \\
\hline 10 & & & $1 \%$ & DM5-1 \\
\hline 11 & & $30 \mathrm{~mm}$ & $1 \%$ & DM3-1 \\
\hline
\end{tabular}

Table 7: Mortar mix variables

\begin{tabular}{|c|c|c|c|c|c|c|c|c|}
\hline $\begin{array}{c}\text { Sample } \\
\text { Name }\end{array}$ & $\begin{array}{c}\text { Fibre } \\
\text { Thickness } \\
(\mathrm{mm})\end{array}$ & $\begin{array}{c}\text { Fibre } \\
\text { Width } \\
(\mathrm{mm})\end{array}$ & $\begin{array}{c}\text { Embedded } \\
\text { Length } \\
(\mathrm{mm})\end{array}$ & $\begin{array}{c}\text { Embedded } \\
\text { Surface Area } \\
\left(\mathrm{mm}^{2}\right)\end{array}$ & $\begin{array}{c}\text { Max Load } \\
\text { at Failure } \\
(\mathrm{N})\end{array}$ & $\begin{array}{c}\text { Failure } \\
\text { Mode }\end{array}$ & $\begin{array}{c}\text { Mechanical } \\
\text { Bond } \\
\text { Strength } \\
\left(\mathrm{N} / \mathrm{mm}^{2}\right)\end{array}$ & $\begin{array}{c}\text { Mean } \\
\text { Bond } \\
\text { Strength } \\
\left(\mathrm{N} / \mathrm{mm}^{2}\right)\end{array}$ \\
\hline S10-A & 0.351 & 2 & 10 & 47.02 & 24.000 & Pull out & 0.51 & \multirow{2}{*}{0.452} \\
\hline S10-B & 0.342 & 2 & 10 & 46.84 & 21.300 & Pull out & 0.455 & 0.391 \\
\hline S10-C & 0.299 & 2 & 10 & 45.98 & 18.000 & Pull out & 0.45 \\
\hline \multicolumn{7}{|c|}{ Table 8: Mechanical bond characteristics - Straight fibres } \\
\hline
\end{tabular}

\begin{tabular}{|c|c|c|c|c|c|c|c|}
\hline $\begin{array}{c}\text { Sample } \\
\text { Name }\end{array}$ & $\begin{array}{c}\text { Fibre } \\
\text { Thickness } \\
(\mathrm{mm})\end{array}$ & $\begin{array}{c}\text { Fibre } \\
\text { Width } \\
(\mathrm{mm})\end{array}$ & $\begin{array}{c}\text { Embedded } \\
\text { Length } \\
(\mathrm{mm})\end{array}$ & $\begin{array}{c}\text { Embedded } \\
\text { Surface Area } \\
\left(\mathrm{mm}^{2}\right)\end{array}$ & $\begin{array}{c}\text { Max Load } \\
\text { at Failure } \\
(\mathrm{N})\end{array}$ & $\begin{array}{c}\text { Failure } \\
\text { Mode }\end{array}$ & $\begin{array}{c}\text { Mechanical } \\
\text { Bond } \\
\text { Strength } \\
\left(\mathrm{N} / \mathrm{mm}^{2}\right)\end{array}$ \\
\hline D10-A & 0.185 & 2 & 10 & 43.7 & 55.6 & Yielding & $>1.272$ \\
\hline D10-B & 0.197 & 2 & 10 & 43.94 & 63.2 & Yielding & $>1.438$ \\
\hline D10-C & 0.235 & 2 & 10 & 44.7 & 71.6 & Yielding & $>1.602$ \\
\hline \multicolumn{7}{|c|}{ Table 9: Mechanical bond characteristics - Deformed fibres }
\end{tabular}




\title{
Early Age Performance and Mechanical Characteristics of Recycled PET Fibre Reinforced Concrete
}

\author{
Ruben Paul Borg ${ }^{1}$, Owen Baldacchino ${ }^{1}$, Liberato Ferrara ${ }^{2}$ \\ ${ }^{1}$ Faculty for the Built Environment, University of Malta, Tal-Qroqq, Msida MSD 2080, Malta, \\ ruben.p.borg@um.edu.mt \\ ${ }^{2}$ Department of Civil and Environmental Engineering, Politencio di Milano, Piazza leonardo da Vinci, Milano, \\ Italy, liberato.ferrara@polimi.it
}
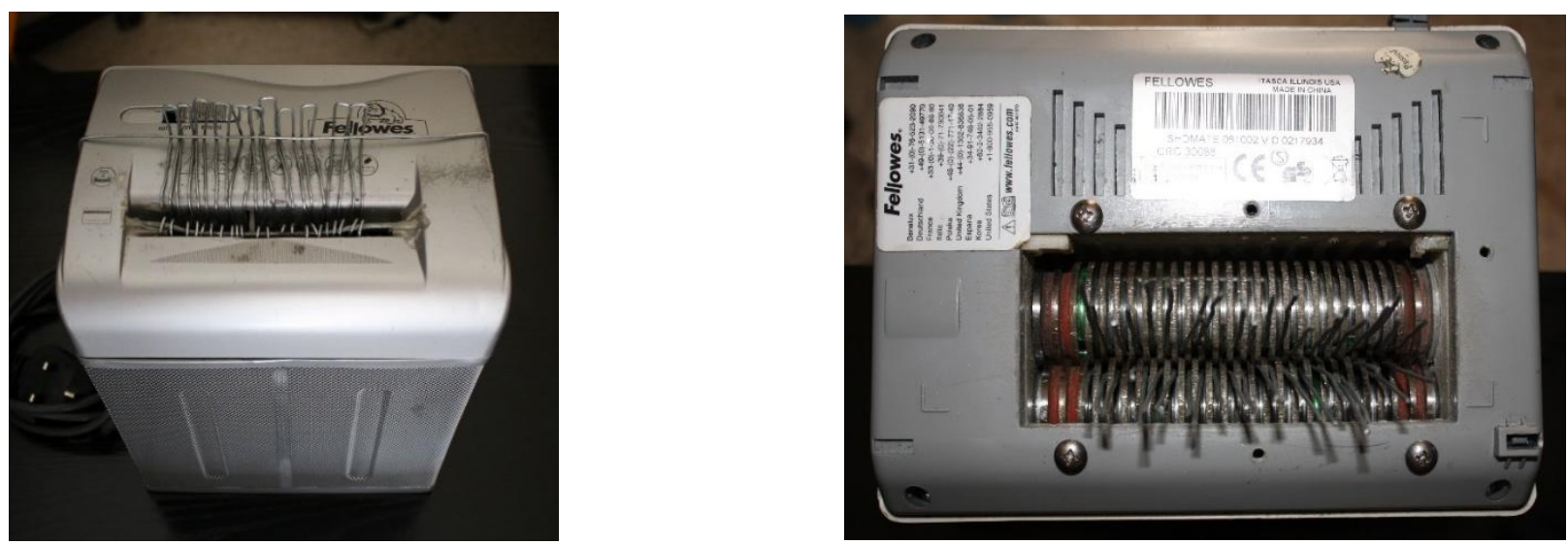

Figure 1: Mechanical shredder used for the cutting of fibres

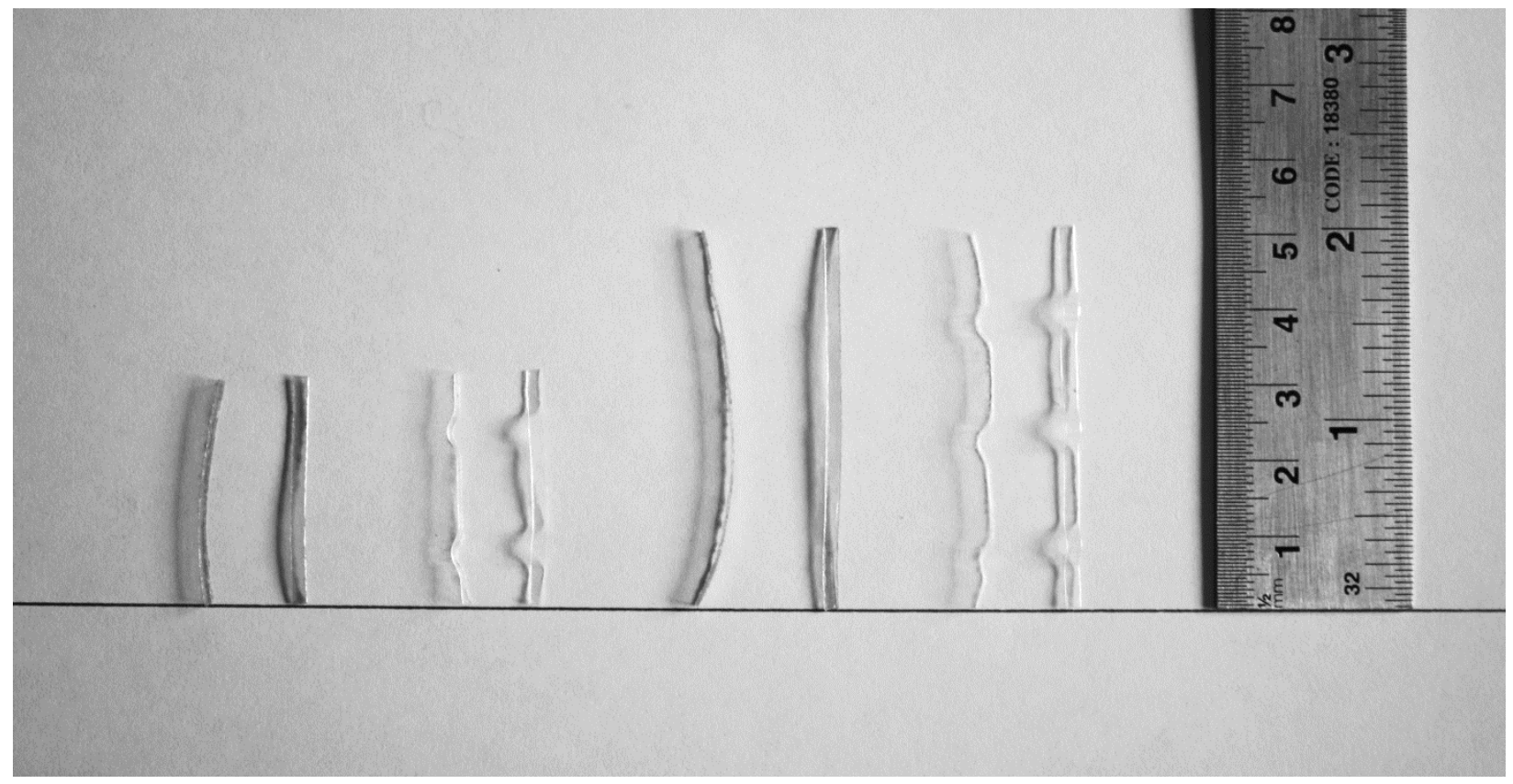


Figure 2: Different fibres used (Straight 3cm, Deformed $3 \mathrm{~cm}$, Straight $5 \mathrm{~cm}$, Deformed $5 \mathrm{~cm}$ )

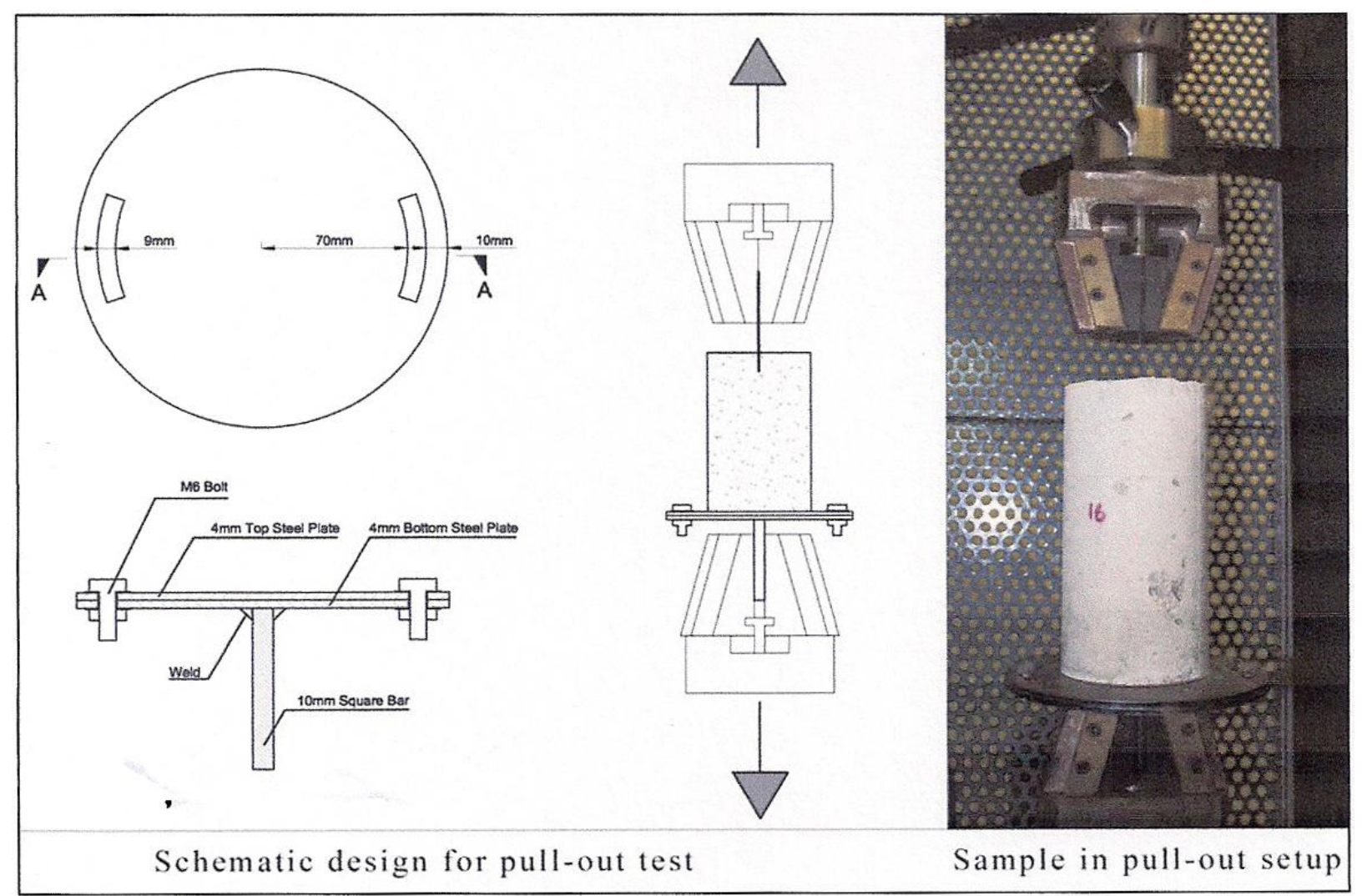

Figure 3: Schematic design and sample for pull-out test

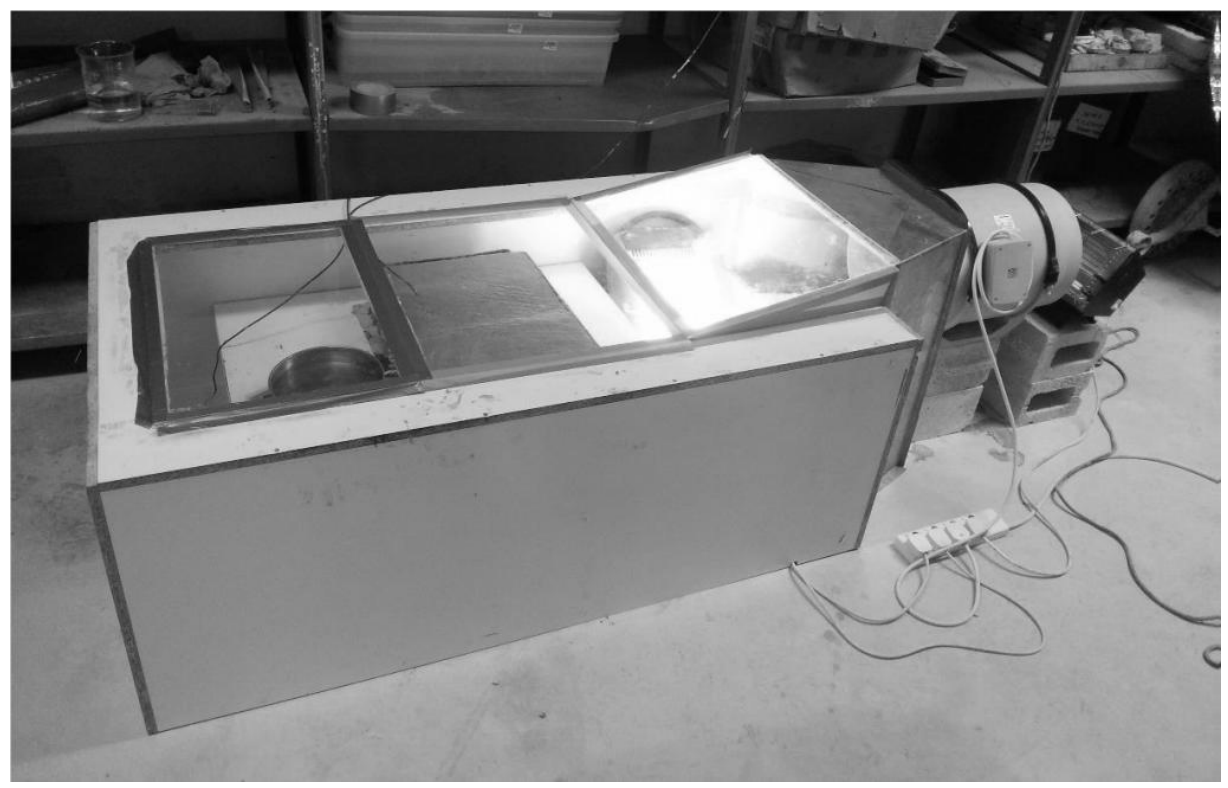

Figure 4: Environmental chamber 


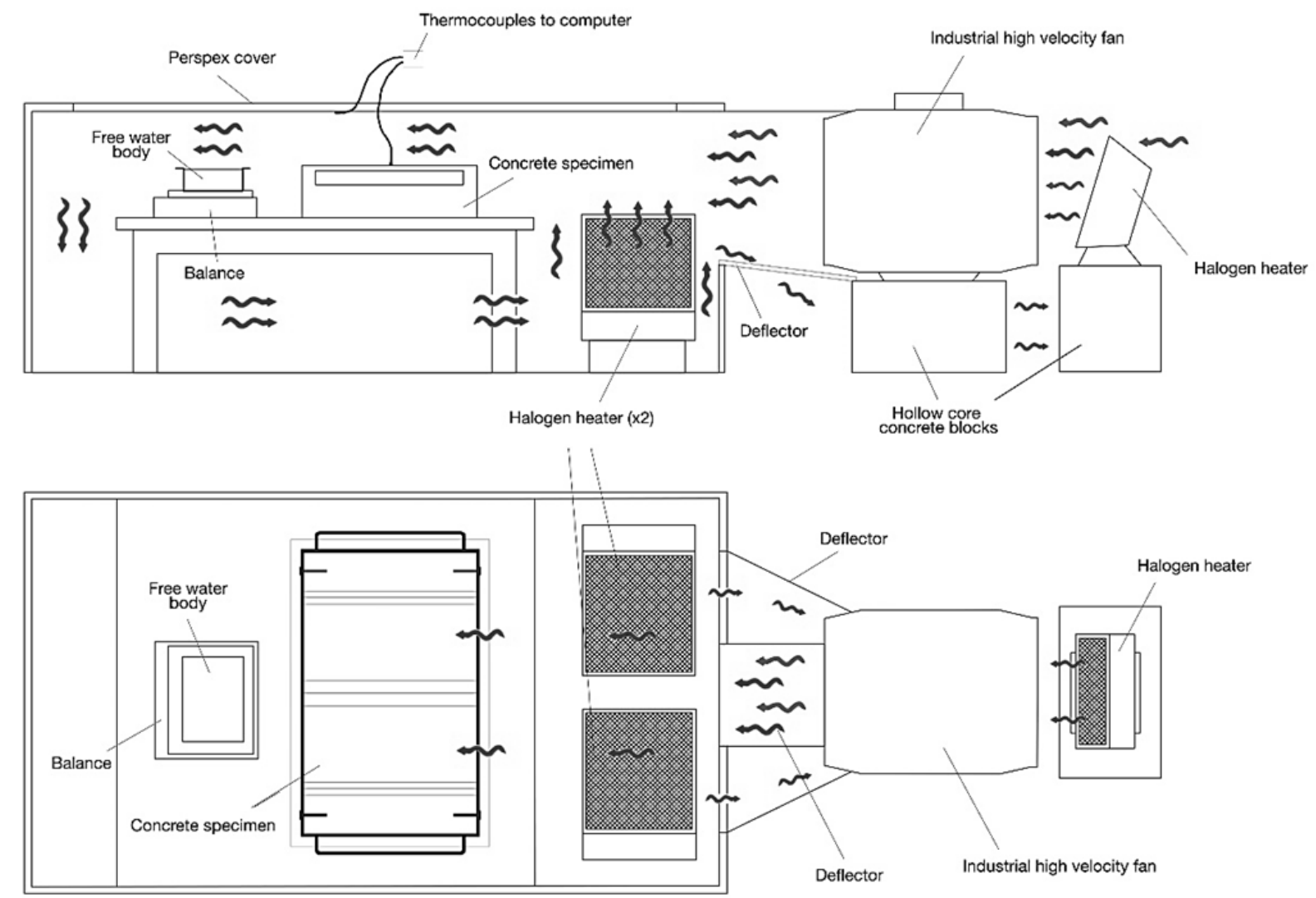

Figure 5: Environmental chamber setup

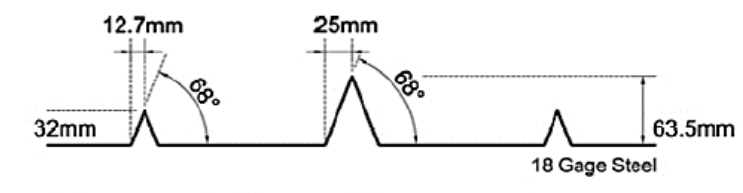

\section{Stress Riser Geometry}

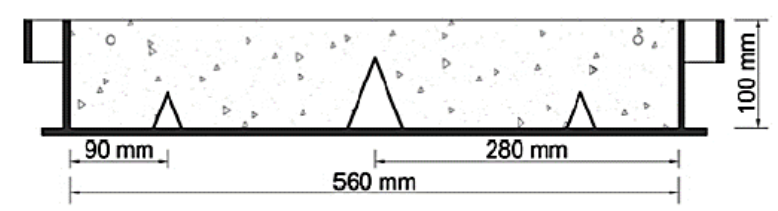

Side View

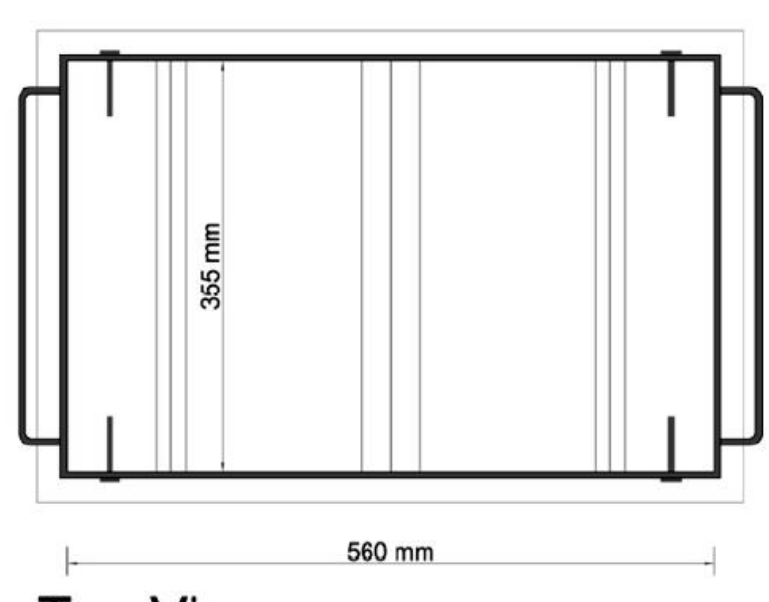

Top View

Figure 6: Specimen mould dimensions 


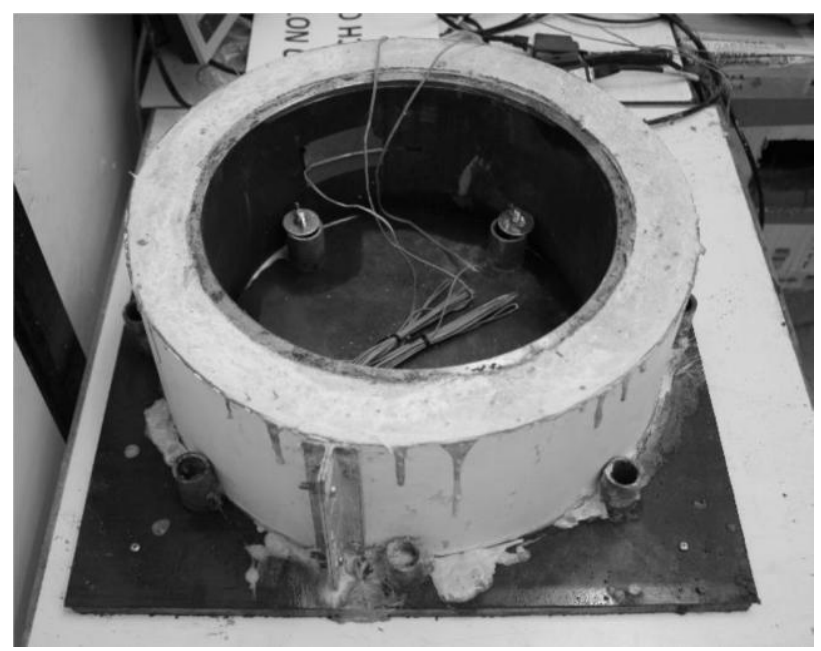

Figure 7: Casted ring specimen
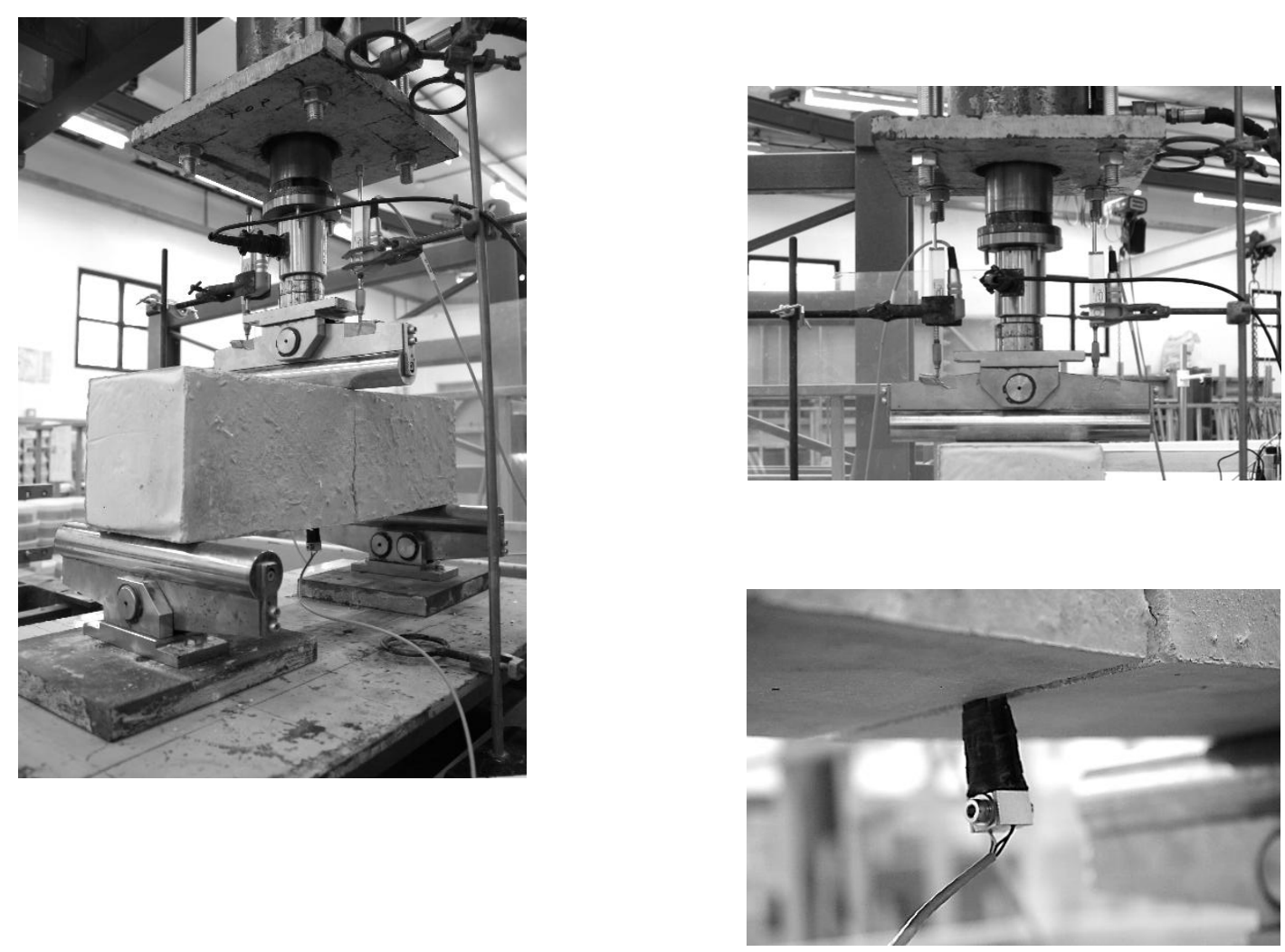

Figure 8 a-c: Flexural test setup, LVDTs and crack transducer 


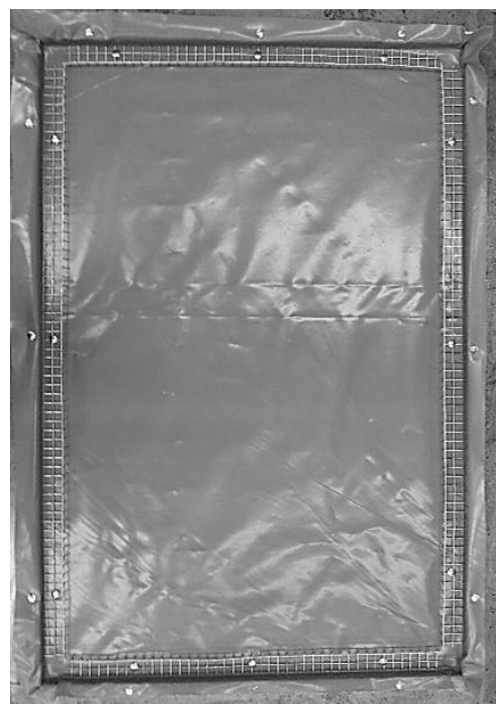

Figure 9a: Kraai panel

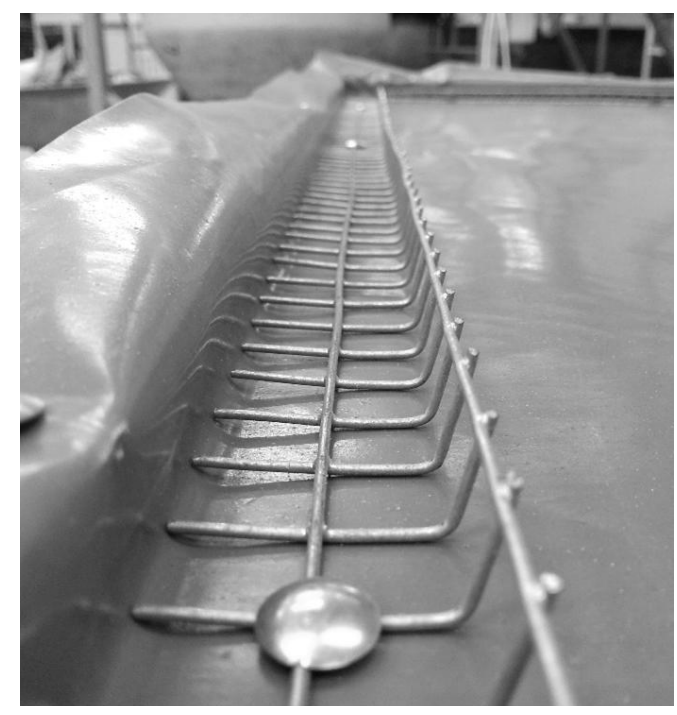

Figure 9b: Steel mesh perimeter restraint

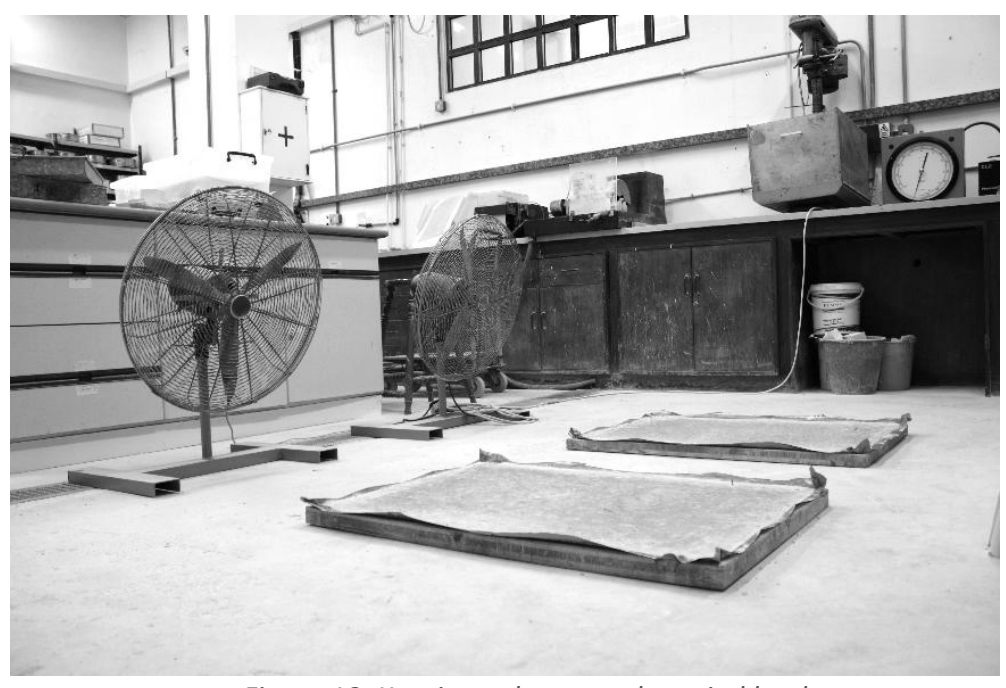

Figure 10: Kraai panels exposed to wind load 

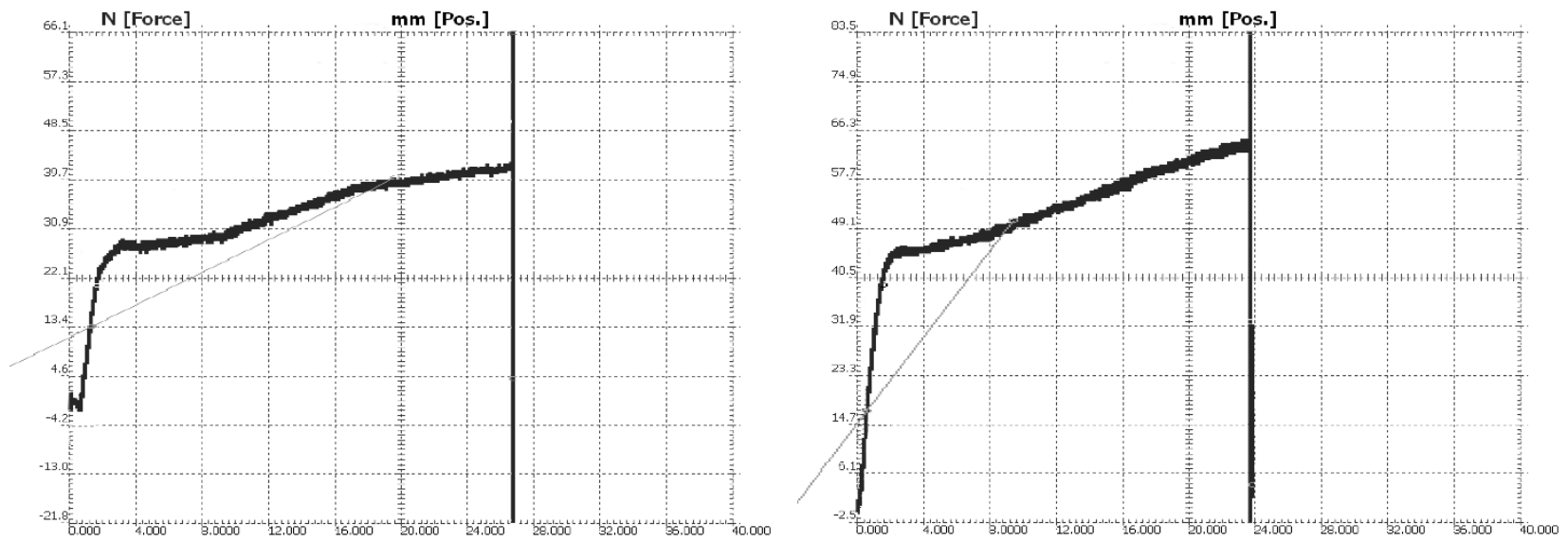

Figure $11 a-b$ : Load displacement graphs - straight fibres

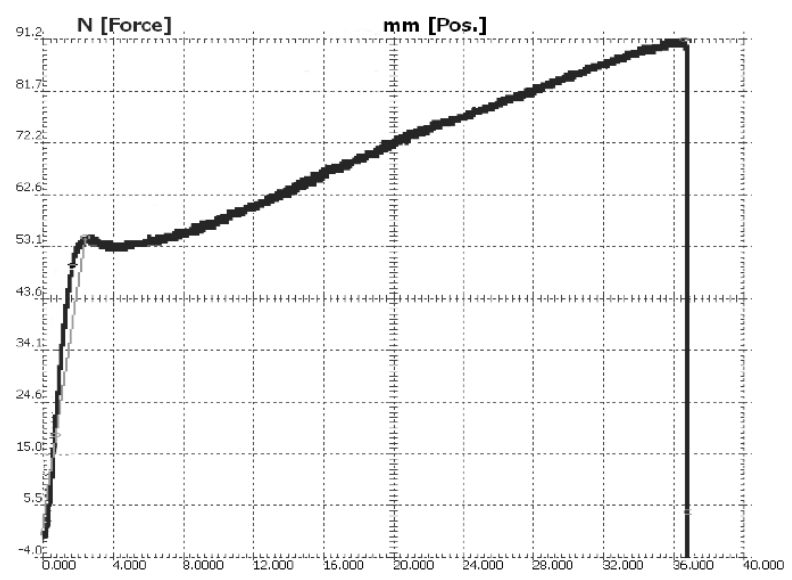

Figure 11 c: Load displacement graphs - straight fibres
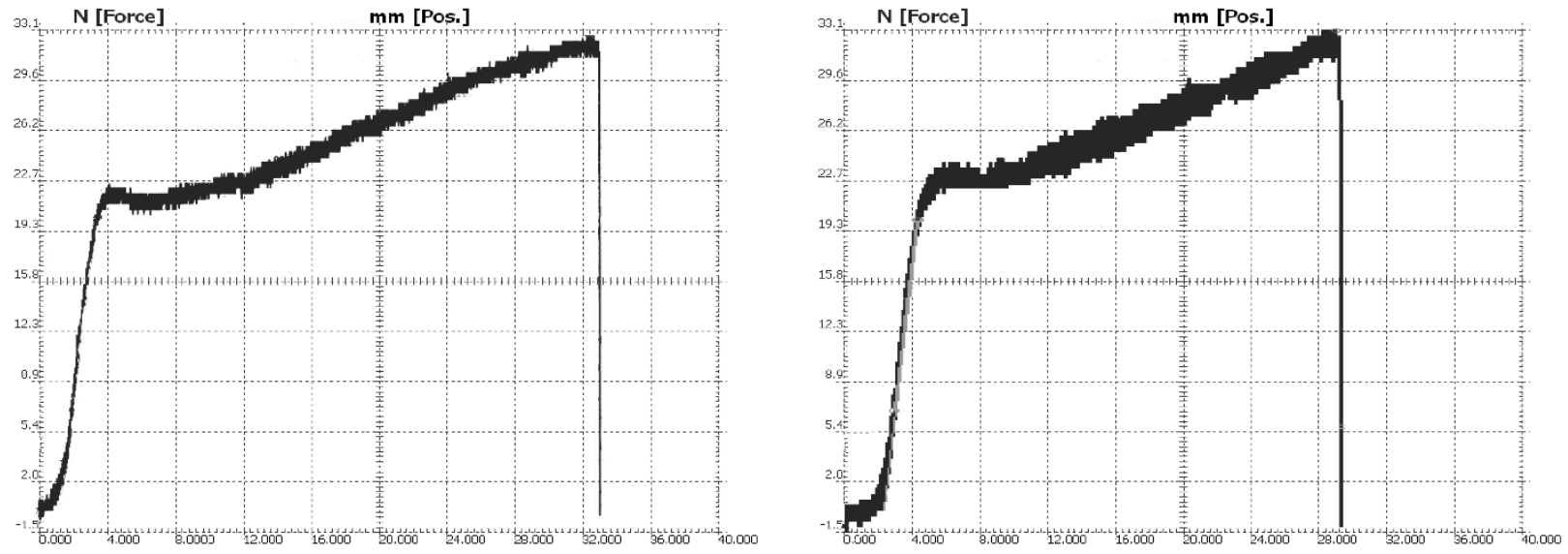


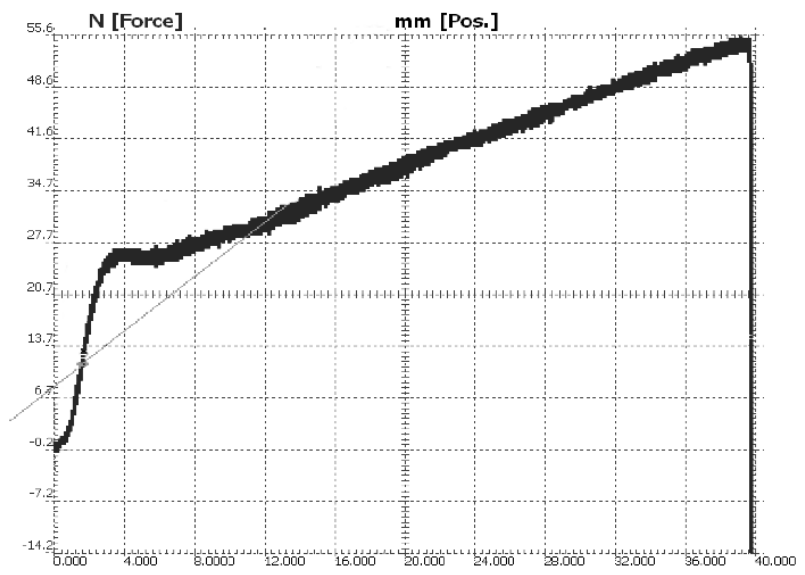

Figure 12 a-c: Load displacement graphs - deformed fibres

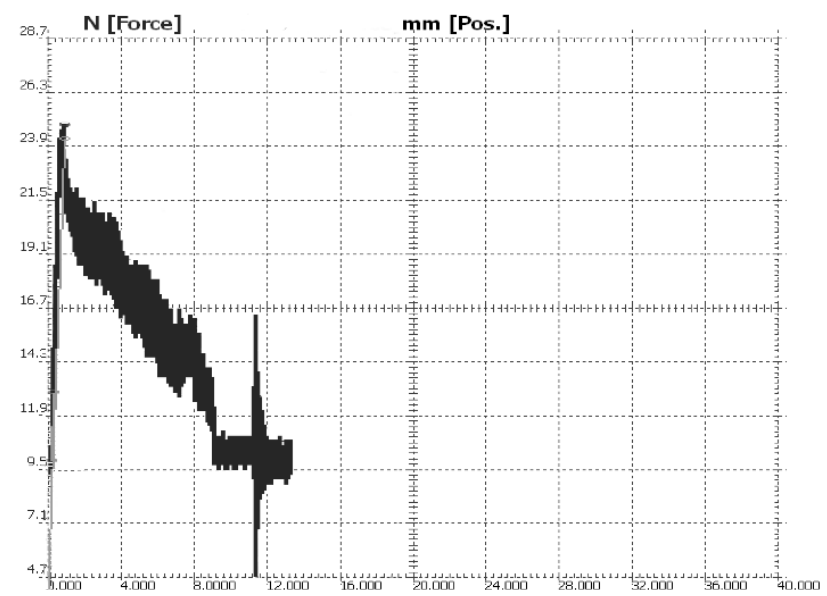

Figure 13: Load displacement curve of sample S10-A

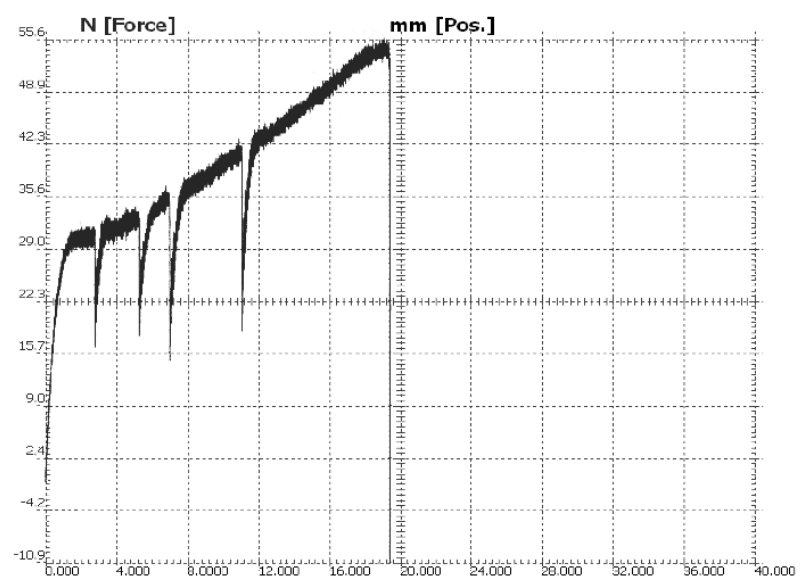

Figure 14: Load displacement graph of sample D10-A 

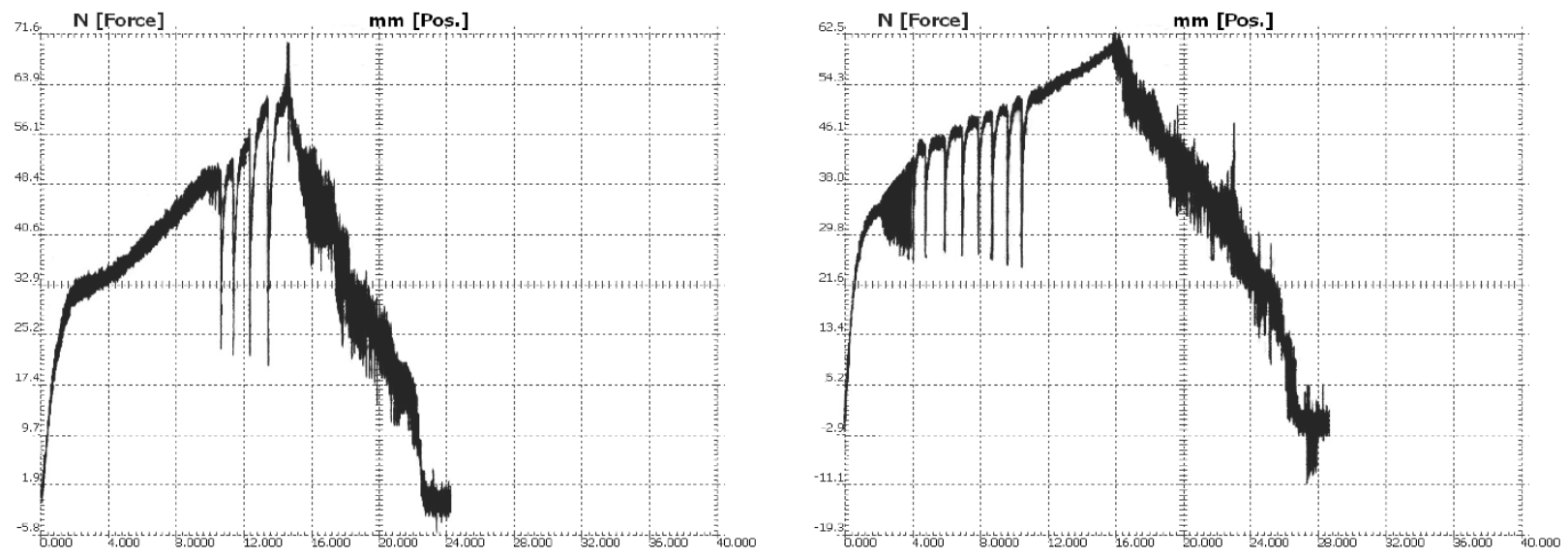

Figure 15 alb: Load displacement graphs $-25 \mathrm{~mm}$ straight fibres

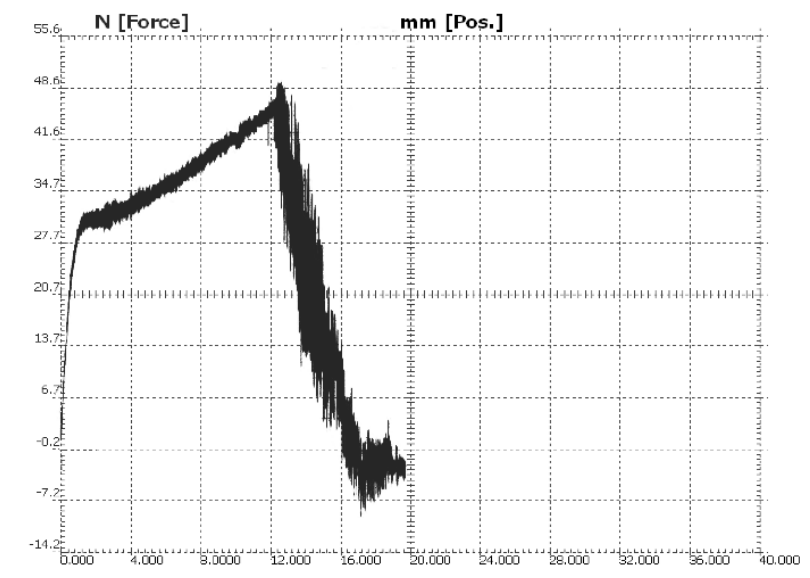

Figure $15 \mathrm{c}$ : Load displacement graphs $-25 \mathrm{~mm}$ straight fibres
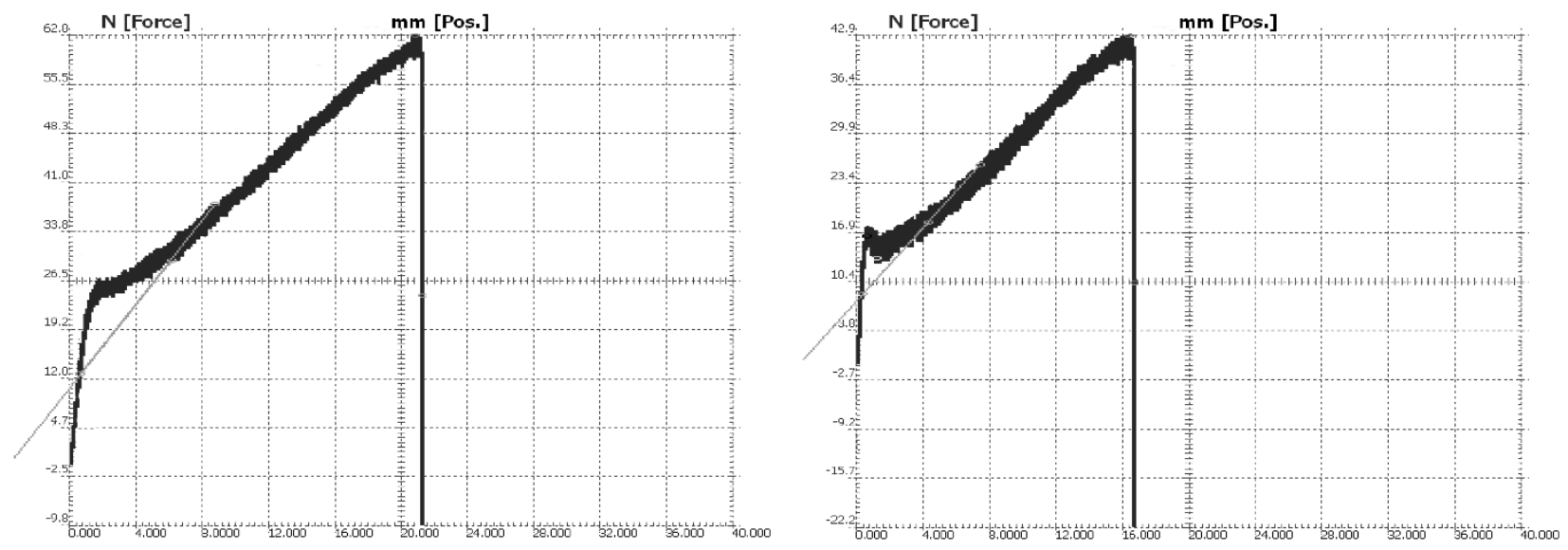


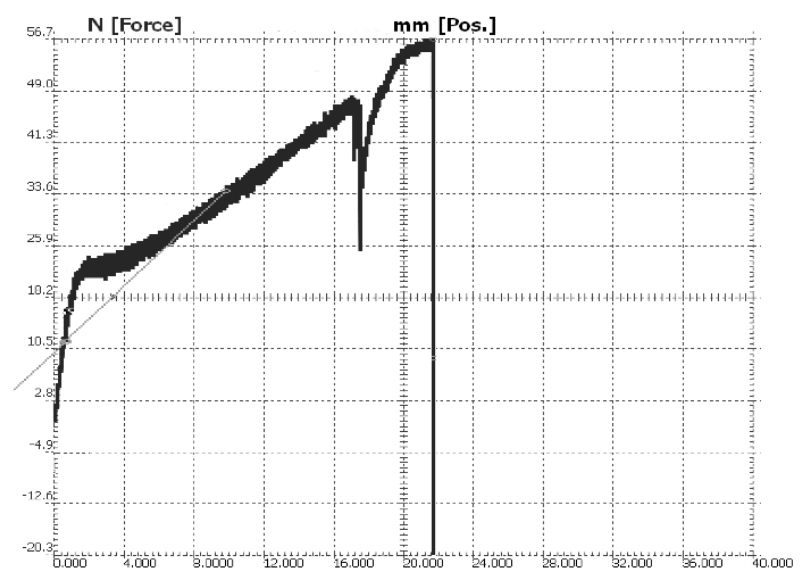

Figure 16 a-c: Load displacement graphs $-25 \mathrm{~mm}$ deformed fibres

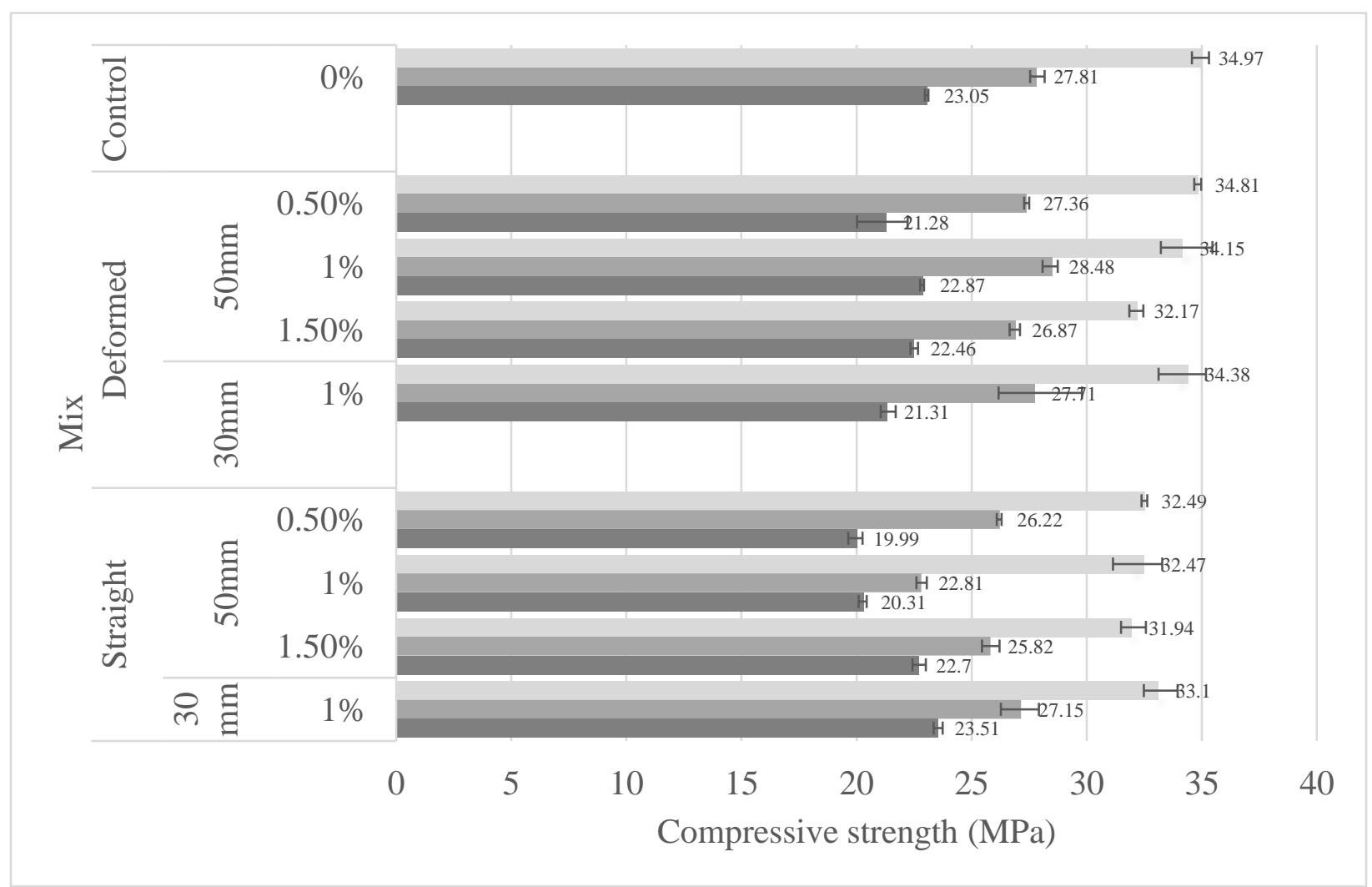

Figure 17: Cube compression results 


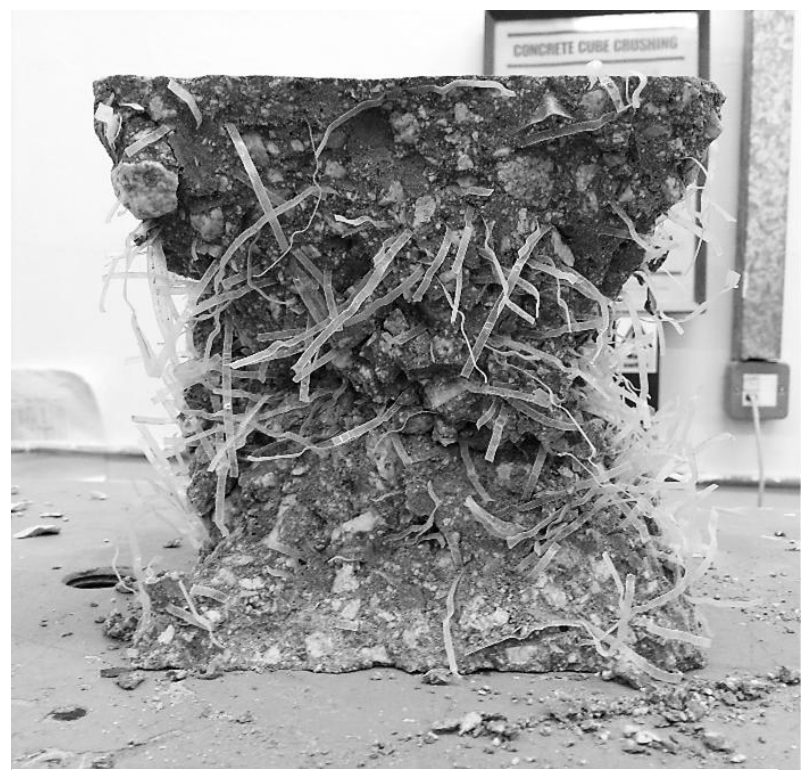

Figure 18a: Deformed fibre-reinforced cube after failure

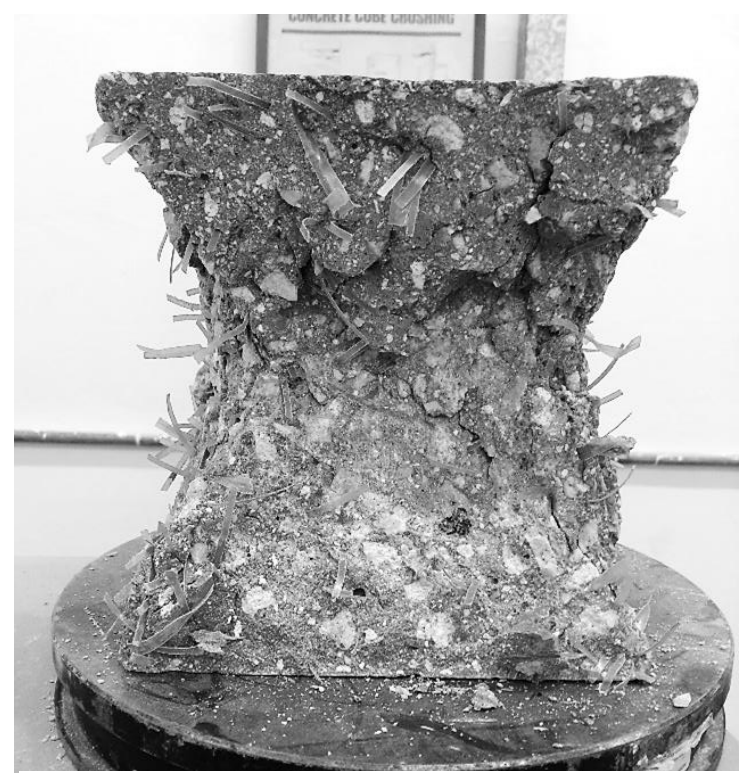

Figure 18b: Straight-fibre reinforced cube after failure

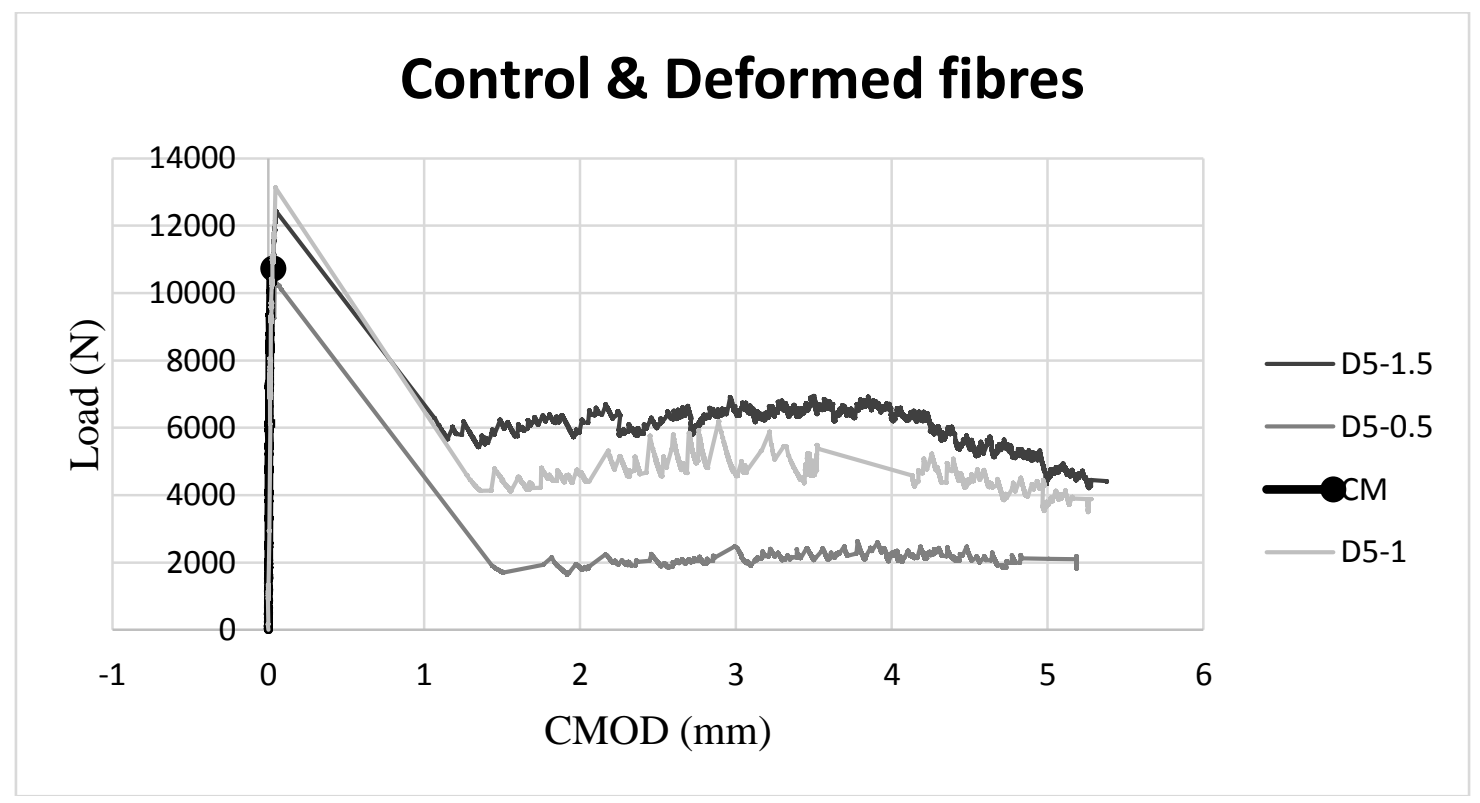

Figure 19: Flexural behaviour of deformed fibre reinforced prisms 


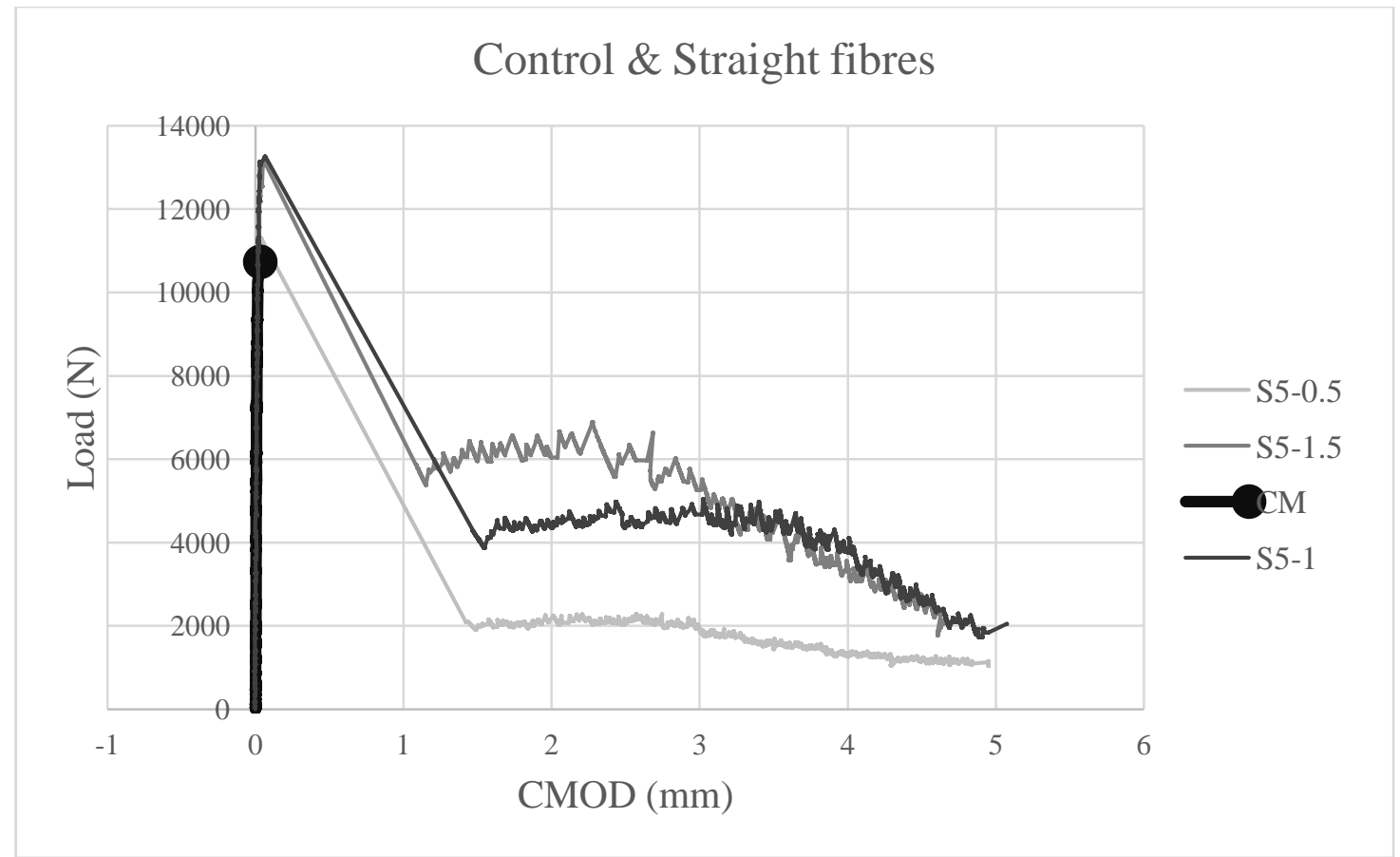

Figure 20: Flexural behaviour of straight fibre reinforced prisms

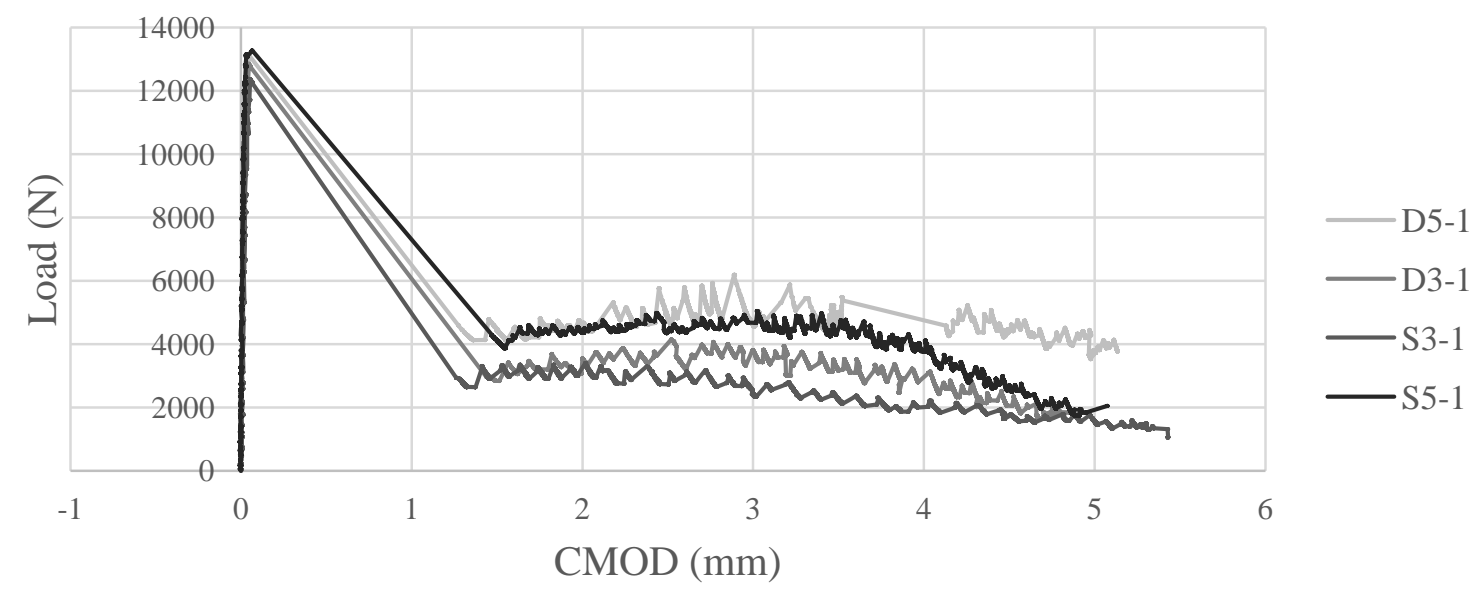

Figure 21: Flexural behaviour of different fibre type and lengths 


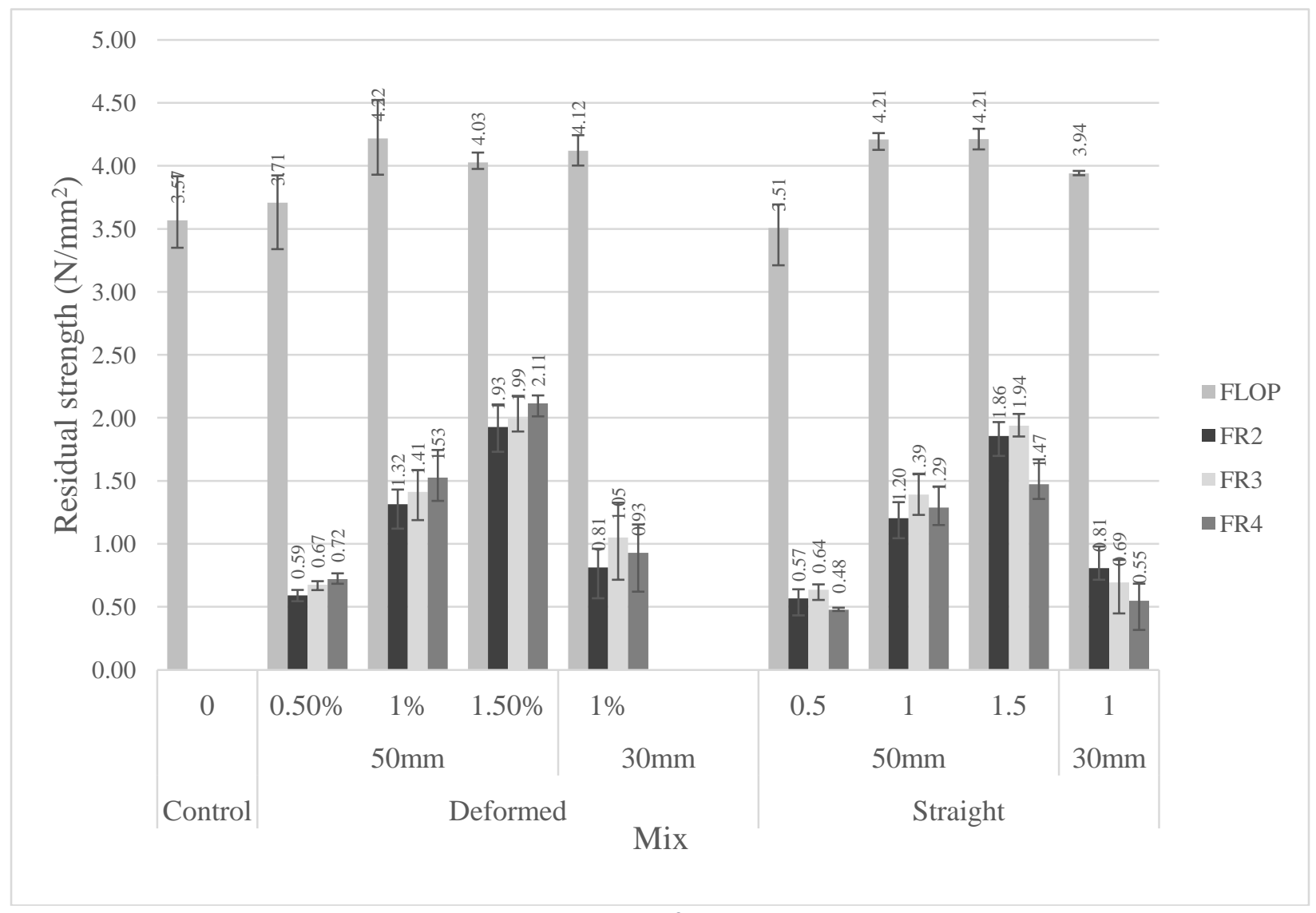

Figure 22: LOP \& residual flexural tensile strength

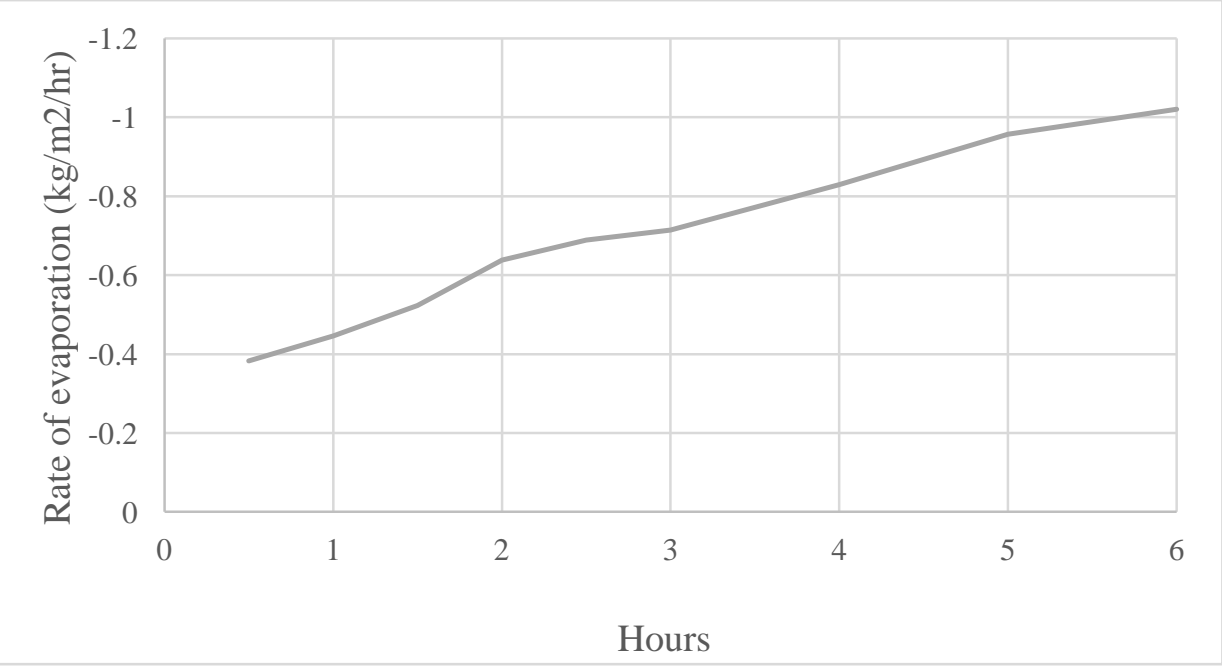

Figure 23: Rate of evaporation 

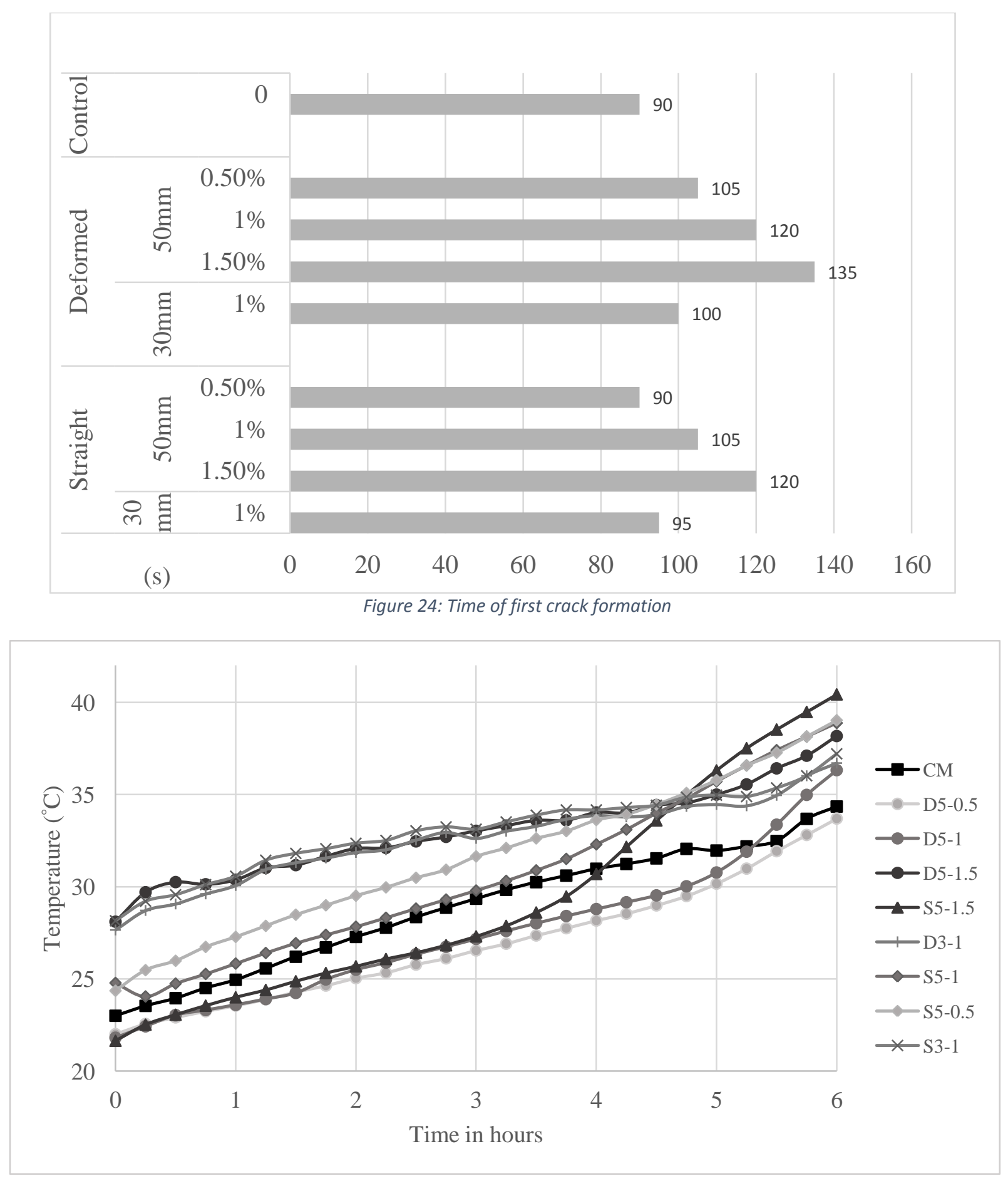

Figure 25: Concrete specimens temperature 


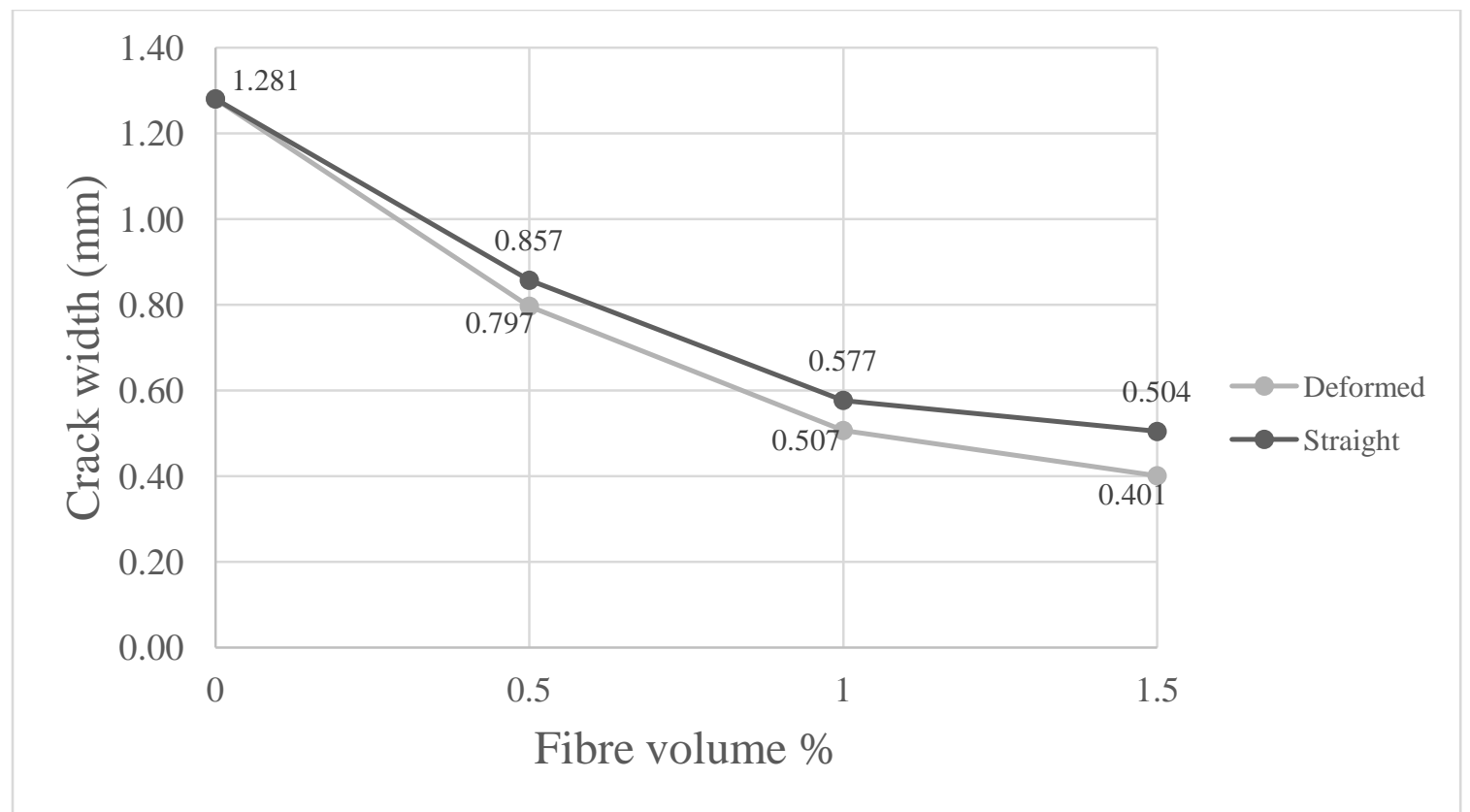

Figure 26: Relationship between fibre volume fraction and crack width

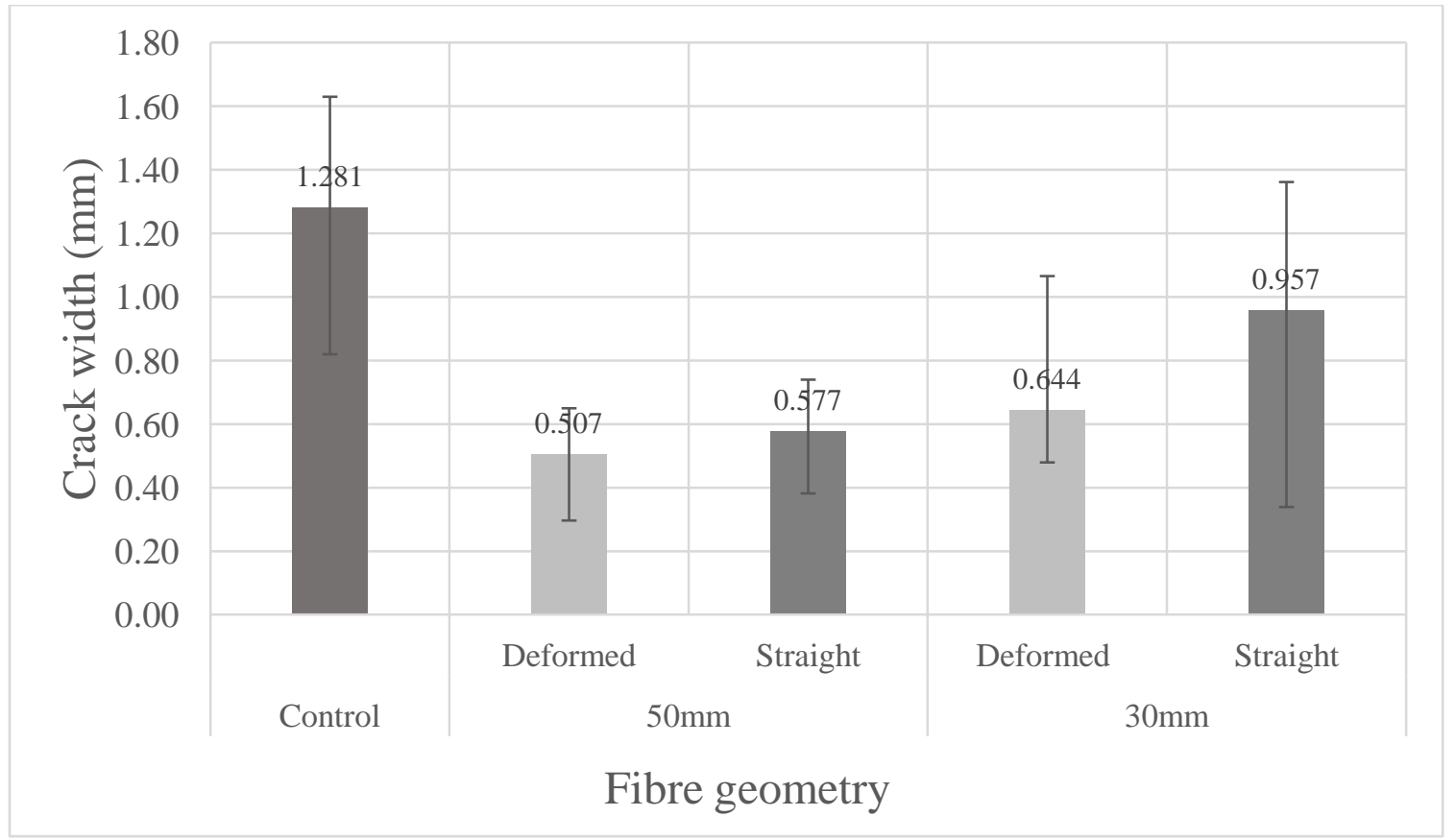

Figure 27: Relationship between fibre length and crack width 


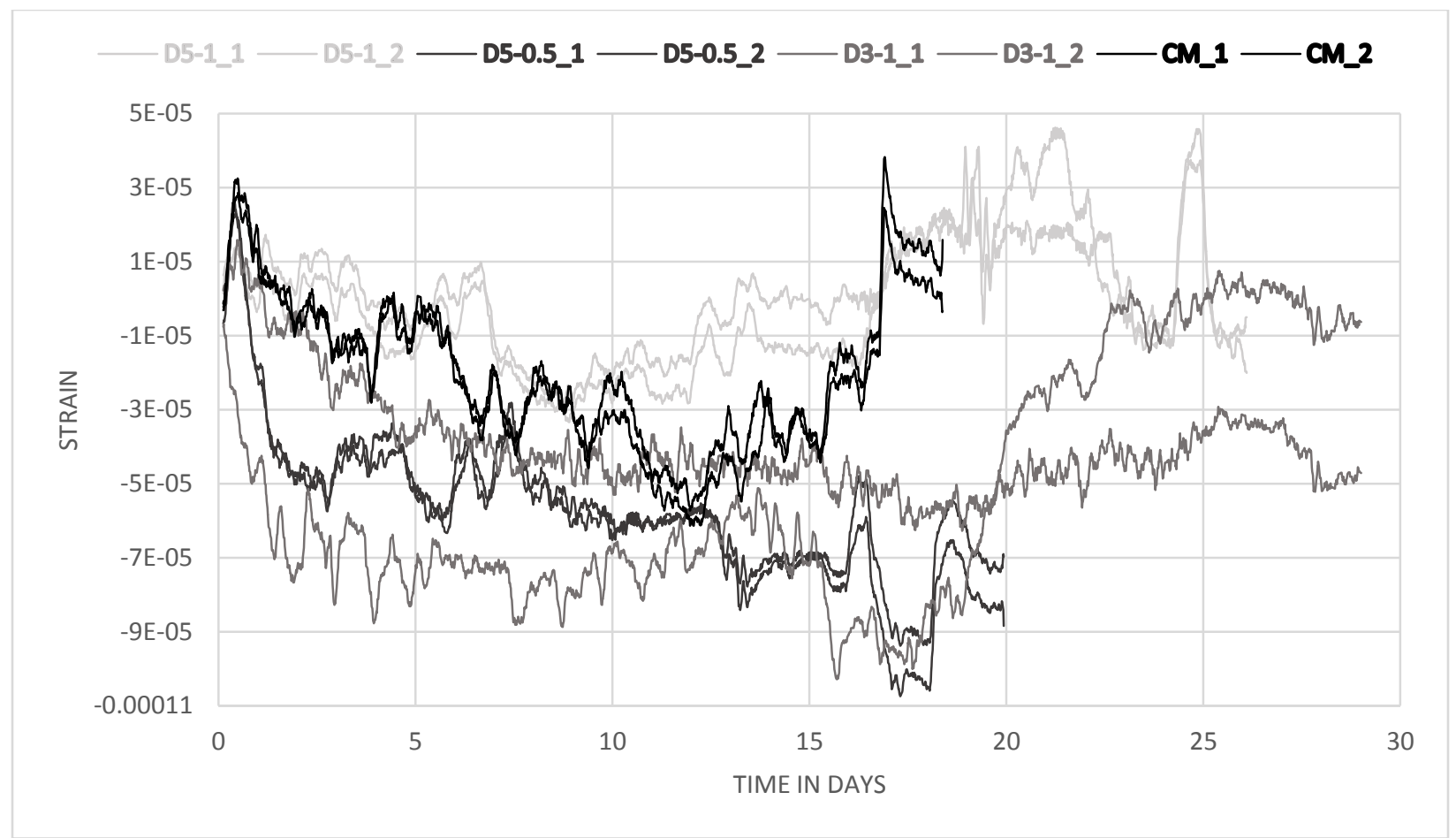

Figure 28: Compressive strain imposed on the ring against time duration
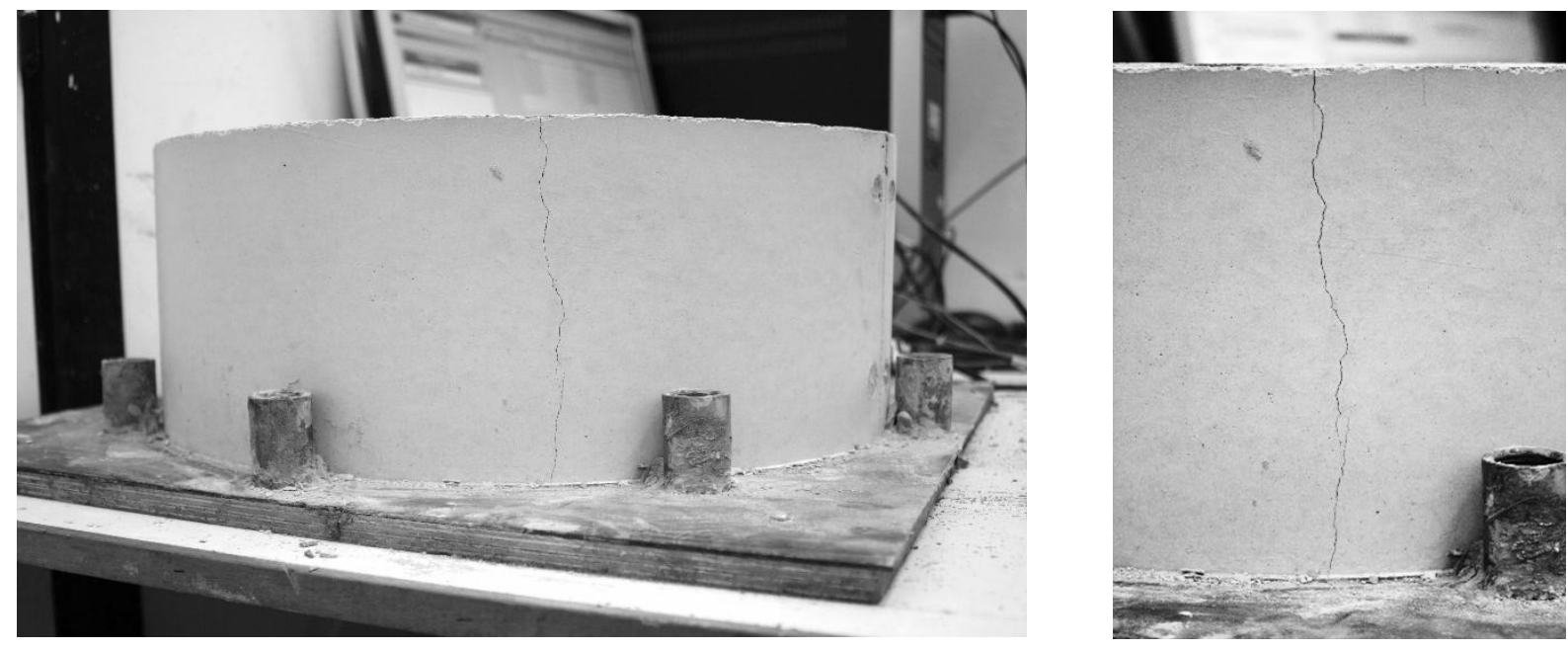

Figure 29a: CM ring specimen

Figure 29b: CM ring test crack 


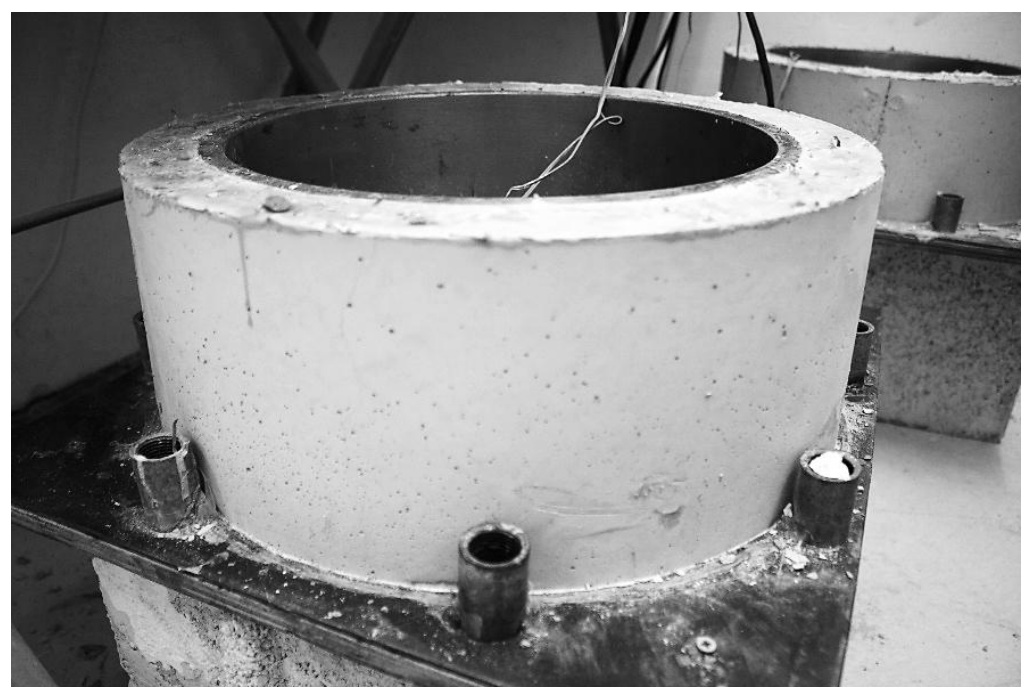

Figure 30a: D5-0.5 ring specimen

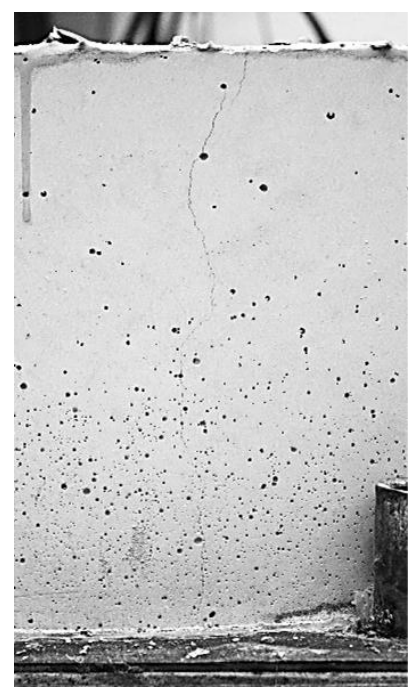

Figure 30b: D5-0.5 ring test crack

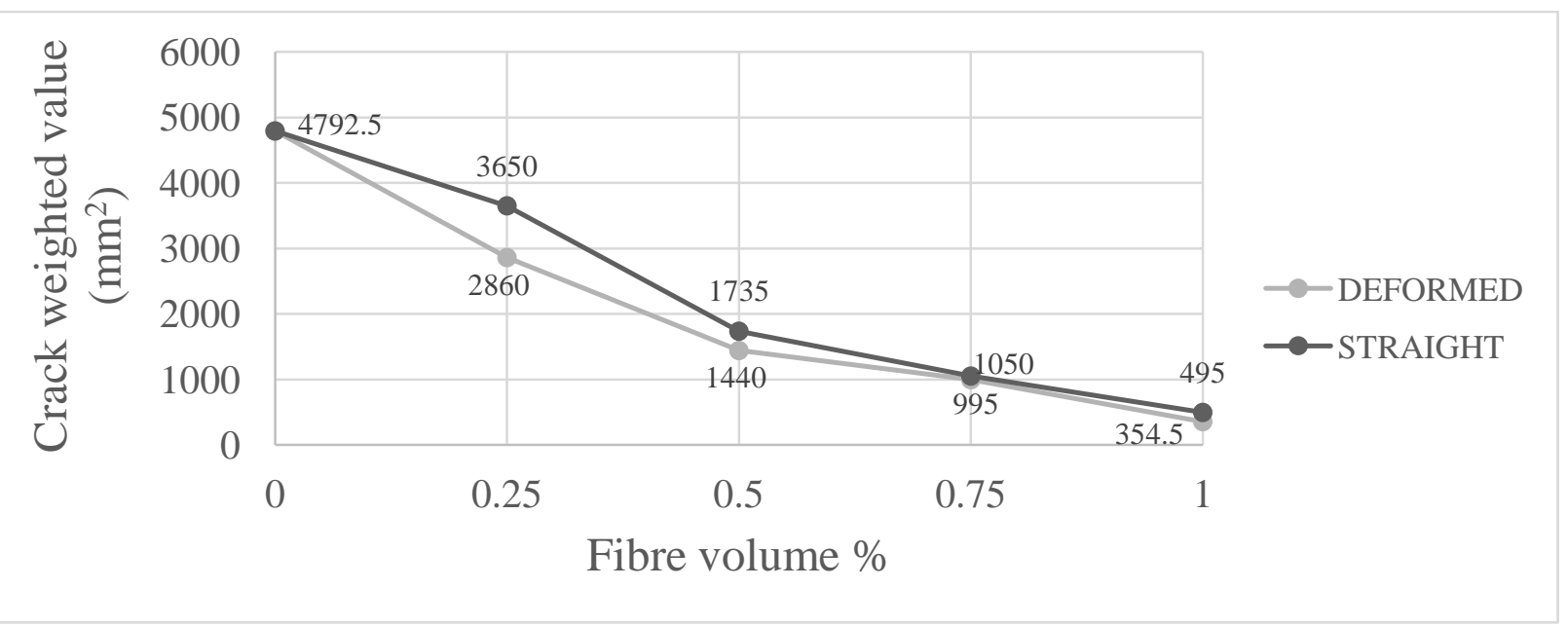

Figure 31: Relationship between crack area and fibre volume fractions 


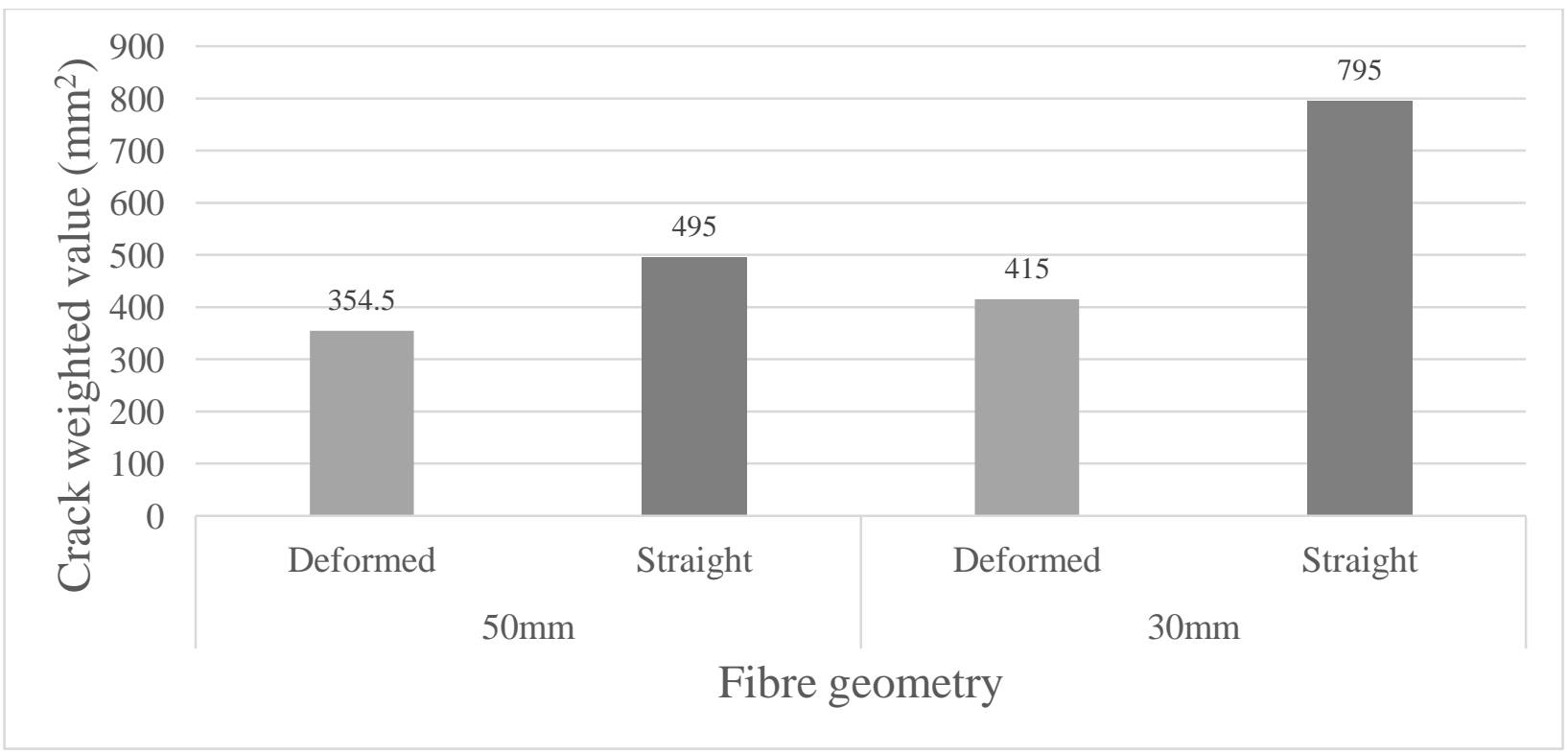

Figure 32: Relationship between crack area, fibre type and length

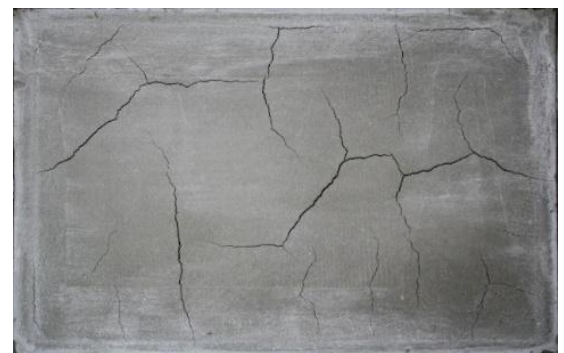

Figure 33a: Control mix panel 


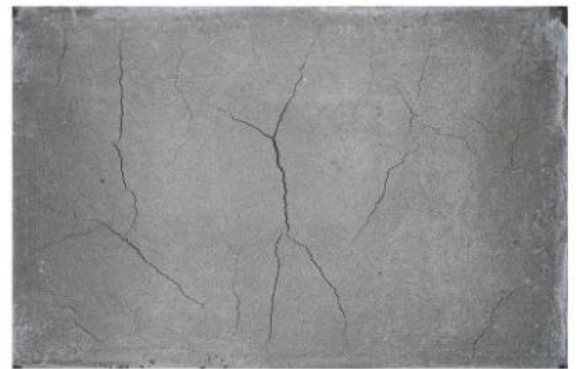

D5-0.25

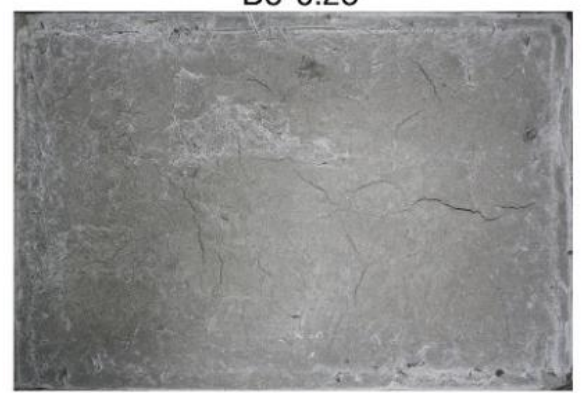

D5-0.5

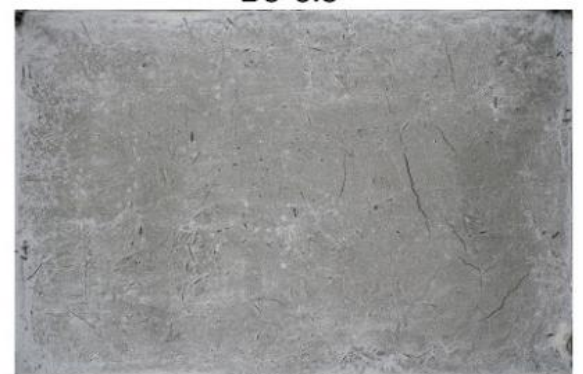

D5-0.75

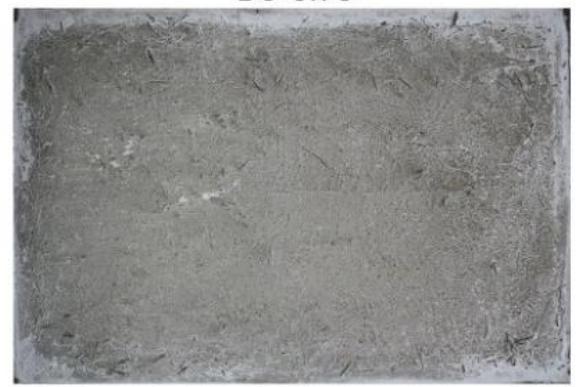

D5-1

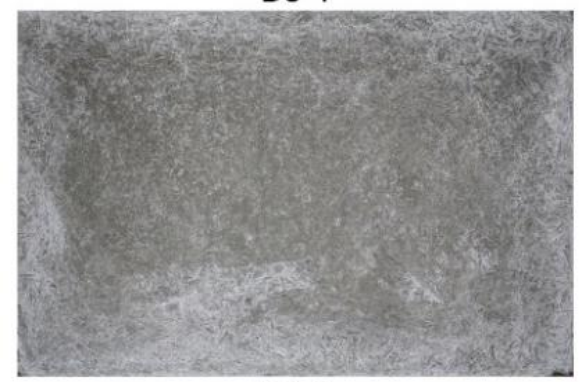

D3-1

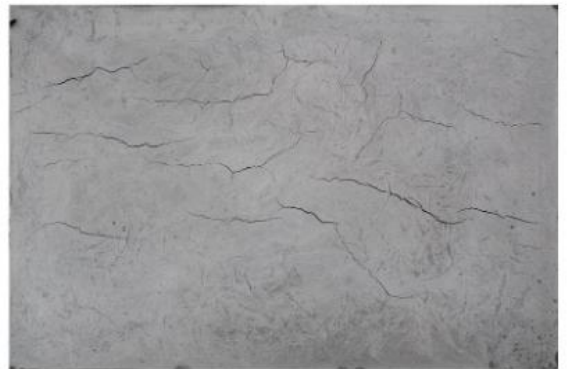

S5-0.25

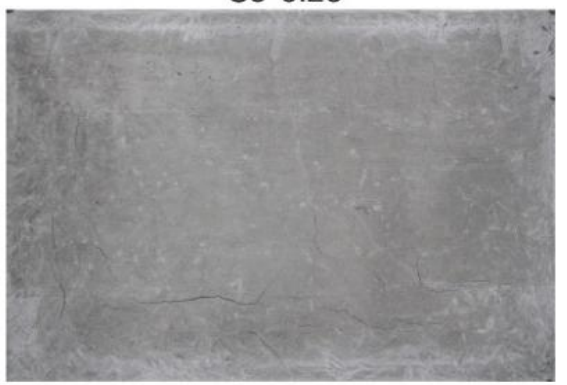

S5-0.5

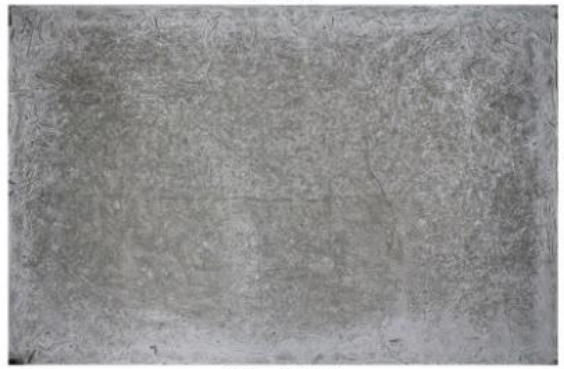

S5-0.75

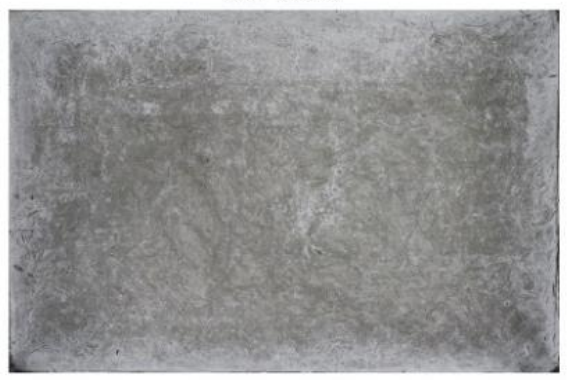

S5-1

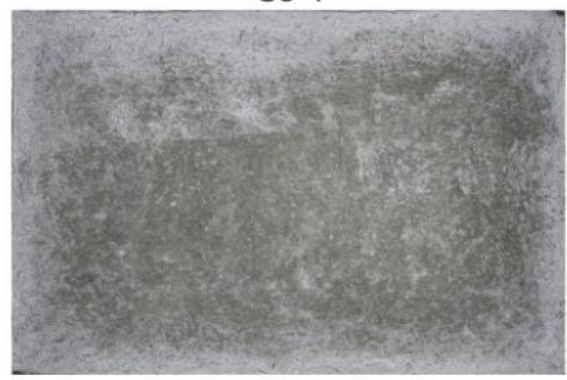

S3-1

Figure 33b: Kraai mix variables panels - crack pattern 